\title{
The Role for Myc in Coordinating Glycolysis, Oxidative Phosphorylation, Glutaminolysis, and Fatty Acid Metabolism in Normal and Neoplastic Tissues
}

\author{
Eric S. Goetzman ${ }^{1}$ and Edward V. Prochownik ${ }^{2,3,4 *}$
}

\begin{abstract}
'Division of Medical Genetics, Children's Hospital of Pittsburgh of UPMC, Pittsburgh, PA, United States, ${ }^{2}$ Division of Hematology/Oncology, Children's Hospital of Pittsburgh of UPMC, Pittsburgh, PA, United States, ${ }^{3}$ Department of Microbiology and Molecular Genetics, University of Pittsburgh Medical Center, Pittsburgh, PA, United States, ${ }^{4}$ University of Pittsburgh Hillman Cancer Center, Pittsburgh, PA, United States
\end{abstract}

OPEN ACCESS

Edited by:

Che-Pei Kung,

Washington University in St. Louis, United States

Reviewed by: Arvin Gouw,

Rare Genomics Institute, United States Eva Surmacz,

Temple University, United States

*Correspondence: Edward V. Prochownik procev@chp.edu

Specialty section: This article was submitted to Cancer Endocrinology, a section of the journal Frontiers in Endocrinology

Received: 19 January 2018 Accepted: 13 March 2018 Published: 12 April 2018

Citation: Goetzman ES and Prochownik EV (2018) The Role for Myc in Coordinating Glycolysis, Oxidative Phosphorylation, Glutaminolysis, and Fatty Acid Metabolism in Normal and Neoplastic Tissues.

Front. Endocrinol. 9:129. doi: 10.3389/fendo.2018.00129
That cancer cells show patterns of metabolism different from normal cells has been known for over 50 years. Yet, it is only in the past decade or so that an appreciation of the benefits of these changes has begun to emerge. Altered cancer cell metabolism was initially attributed to defective mitochondria. However, we now realize that most cancers do not have mitochondrial mutations and that normal cells can transiently adopt cancer-like metabolism during periods of rapid proliferation. Indeed, an encompassing, albeit somewhat simplified, conceptual framework to explain both normal and cancer cell metabolism rests on several simple premises. First, the metabolic pathways used by cancer cells and their normal counterparts are the same. Second, normal quiescent cells use their metabolic pathways and the energy they generate largely to maintain cellular health and organelle turnover and, in some cases, to provide secreted products necessary for the survival of the intact organism. By contrast, undifferentiated cancer cells minimize the latter functions and devote their energy to producing the anabolic substrates necessary to maintain high rates of unremitting cellular proliferation. Third, as a result of the uncontrolled proliferation of cancer cells, a larger fraction of the metabolic intermediates normally used by quiescent cells purely as a source of energy are instead channeled into competing proliferation-focused and energy-consuming anabolic pathways. Fourth, cancer cell clones with the most plastic and rapidly adaptable metabolism will eventually outcompete their less well-adapted brethren during tumor progression and evolution. This attribute becomes increasingly important as tumors grow and as their individual cells compete in a constantly changing and inimical environment marked by nutrient, oxygen, and growth factor deficits. Here, we review some of the metabolic pathways whose importance has gained center stage for tumor growth, particularly those under the control of the c-Myc (Myc) oncoprotein. We discuss how these pathways differ functionally between quiescent and proliferating normal cells, how they are kidnapped and corrupted during the course of transformation, and consider potential therapeutic strategies that take advantage of common features of neoplastic and metabolic disorders.

Keywords: fatty acid oxidation, glutaminolysis, glycolysis, mitochondria, oxidative phosphorylation, Randle cycle, Warburg effect 


\section{THE ABNORMAL METABOLISM OF CANCER CELLS: GLYCOLYSIS VERSUS OXIDATIVE PHOSPHORYLATION (OXPHOS) AND BEYOND}

The distinct metabolic behaviors of cancer cells have been appreciated since the 1950s when Otto Warburg first observed their high rates of glycolysis even when there was sufficient oxygen present to support OXPHOS (1-4). Such "aerobic glycolysis," now termed the Warburg effect, was initially attributed to defective mitochondria but is now known to occur in rapidly growing normal cells and in cancers with no identifiable mutations in genes encoding mitochondrial proteins. More recently, the reprogramming of glutamine and fatty acid metabolism has also been identified in cancer cells (5-10). The still evolving consensus formulated over the past several years is that the altered metabolism of cancer cells is one of their so-called "hallmark" characteristics (11) and is both a direct and indirect consequence of oncogene and tumor suppressor gene mis-expression and/or mutation. Much less commonly does reprogramming occur as the result of metabolic gene mutation $(12,13)$. The two main advantages that metabolic re-wiring imparts to cancer cells are the ability to ensure sustained supplies of anabolic building blocks and to generate the energy needed for their assembly into macromolecules. This supports several other cancer hallmarks, including survival, sustained proliferation, tissue invasion and metastasis, and the participation in tumor-initiated angiogenesis (11).

Several general themes have begun to emerge from the study and cataloging of tumor-specific metabolic changes. One of these is that normal and malignant cells typically use the same basic metabolic pathways, which are deregulated in the latter and thus run at markedly different rates and/or are utilized to achieve different ends. For example, normal quiescent cells utilize glycolysis predominantly to generate small amounts of ATP (2 molecules/molecule of glucose) and pyruvate. Pyruvate is then completely oxidized by the TCA cycle within mitochondria to generate the reducing equivalents needed to power the electron transport chain (ETC) and to generate considerably more ATP ( $\sim 36$ additional molecules). By contrast, cancer cells often utilize glycolysis at an exaggerated pace for the same energy-generating purpose but also as a source of anabolic precursors to support rapid proliferation. For example, pyruvate is the initial substrate for the biosynthesis of alanine, aspartate, and threonine, and pyruvate's immediate upstream precursor, phosphoenol pyruvate (PEP), is the starting substrate for tyrosine, tryptophan, and phenylalanine. The even more proximal glycolytic intermediate 3-phosphoglycerate can be directed into the synthesis of glycine and serine as well as purine nucleotides and the initial product of glucose catabolism, glucose-6-phosphate, can be diverted into the anabolic pentose phosphate pathway (PPP). TCA cycle intermediates such as citrate, succinyl coenzyme A ( $\mathrm{CoA})$, and oxaloacetate may also be used in non-mitochondrial biosynthetic pathways to furnish additional anabolic substrates for lipid, amino acid, and nucleotide biosynthesis, respectively. Any resulting depletion of these substrates from their mitochondrial stores may then be addressed by mobilizing the so-called anaplerotic (or "filling in") reactions such as the conversion of glutamine to $\alpha$-ketoglutarate, the $\beta$-oxidation of odd-chain fatty acids to succinyl-CoA, and the carboxylation of pyruvate to oxaloacetate.

Another theme is that these metabolic pathways are highly flexible and responsive in ways that ultimately benefit the growth and survival of the transformed cell. Indeed, cells with the most adaptable pathways will eventually outcompete their more metabolically rigid peers and be favored to survive and clonally expand over the course of tumor evolution. Such metabolic plasticity is particularly advantageous given the rapidity and extent to which the tumor microenvironment can change and the relatively small distances over which these changes can occur (14-17). The consequences of an inimical metabolic environment, which normally might promote cell cycle arrest or death, might be further assuaged by virtue of the loss of proapoptotic pathways mediated by TP53 and other tumor suppressors. In some cases, these losses not only delay or inhibit the apoptotic response to nutrient deprivation or the reactive oxygen species (ROS) associated with them but can themselves further alter metabolic pathways in favor of survival $(18,19)$. Maximizing survival and proliferation as a consequence of metabolic adaptability can also allow for the acquisition of additional mutations that further contribute to tumor evolution and adaptability (20).

Finally, a third theme is that some cancer-related metabolic reprogramming generates metabolites that can dramatically impact tumor behavior and even alter gene expression profiles. These effects can be direct or indirect, and the metabolites can either be the normal products of cellular respiration or the socalled "onco-metabolites," which possess neomorphic properties and are generated as a consequence of mutations in mitochondrial enzymes. Examples of the first type include the excessive lactate generated by high rates of Warburg-type glycolysis. Lactate excretion lowers extracellular $\mathrm{pH}$, thereby potentiating certain extracellular proteases and thus facilitating tumor invasiveness and metastatic spread (21). Lactate also upregulates vascular endothelial growth factor and hypoxia-inducible factor 1 alpha (HIF-1 $\alpha$ ), an oxygen-sensitive transcription factor that positively regulates glycolysis, particularly in collaboration with c-Myc (Myc), which is deregulated in the majority of human cancers (22-26). Furthermore, lactate, as well as Myc, can impart radioresistance in some tumors and contribute to the escape from immune surveillance (27-30). Tumor-generated lactate can also stimulate neighboring fibroblasts to increase their synthesis and release of hyaluronan, an extracellular high-molecular weight glycosaminoglycan, which increases motility and facilitates tumor cell spread (31). Point mutations in the TCA cycle enzymes isocitrate dehydrogenase (IDH) 1 or IDH2, most of which have been described in myeloid leukemias and gliomas (32-35), can cause the enzymes to generate the novel onco-metabolite D-R2-hydroxyglutarate (D-R-2HG) rather than the normal TCA cycle intermediate $\alpha$-ketoglutarate. D-R-2HG is a potent inhibitor of the Ten-Eleven Translocation 2 protein that normally converts 5-methylcytosine to 5-hydroxymethylcytosine, a reaction that serves as an intermediate step in DNA de-methylation $(32,36$, 37). In a variation of this theme, both hypoxia- and lactatemediated intracellular acidification can impart new catalytic properties to the enzymes lactate dehydrogenase (LDH) and 
malate dehydrogenase, allowing them to switch their normal substrate preferences and instead convert $\alpha$-ketoglutarate to a $2 \mathrm{HG}$ enantiomer, L-S-2HG, which is also a potent epigenetic regulator (38-40). Finally, in an example that combines each of the above mechanisms, the accumulation of succinate, due to inactivating mutations in any one of the four subunits of the heterotetrameric succinate dehydrogenase (SDH) complex, has been linked to paragangliomas, pheocytochromocytomas, and gastrointestinal stromal cell tumors. While the exact mechanism by which excess succinate leads to transformation and why it is only associated with these rare tumor types are currently unknown, suspected culprits include excess ROS, HIF- $1 \alpha$ stabilization, aberrant genome methylation, and tumor-promoting inflammatory changes (41-43).

Here, we review some of the major metabolic pathways that go awry in cancer, particularly those under the purview of Myc, and attempt to relate these to normal metabolic functions. It is important to emphasize that our focus on Myc arises from the fact that it is among the most frequently deregulated oncoproteins across all cancer types, is virtually never mutated, and regulates numerous metabolic functions $(5,22,24,44-46)$. Thus, metabolic alterations attributable to Myc are due to quantitative and not qualitative differences in its behavior, thus making it somewhat easier to understand its role in normal metabolic processes. Myc's wide-spread overexpression in cancer can most likely be attributed to the fact that it is a major transcriptional integrator of most, if not all, normal and oncogenic growth factor pathways (22, 24, 44-47). Understanding how Myc reprograms metabolic pathways can explain much of how they are altered by upstream mutant oncoproteins that constitutively upregulate Myc expression. Moreover, the most prominent transcript families under Myc's control tend to encode proteins that supervise energy production, anabolic pathways, protein synthesis, and cell cycle progression, all of which intimately impact both tumor and normal cell growth and survival and likely explain why many tumors are "addicted" to Myc (22, 45, 47-50). The differential regulation of these pathways by Myc permits unique glimpses into how they respond to different levels of this central transcriptional regulator while providing a basis for understanding why pharmacologic inhibition of Myc is considered a "Holy Grail" in cancer therapy and why it may also be useful in the treatment of non-malignant diseases of excessive cell proliferation $(51,52)$. We also summarize how certain pathways under Myc's influence differ functionally in quiescent and proliferating normal cells and how they are altered in tumors by Myc's deregulated expression $(22,24,44)$.

\section{THE EARLY DAYS: HINTS THAT MYC (AND OTHER ONCOGENES) REGULATE CELLULAR METABOLISM}

In the aftermath of the initial discovery that Myc is the cellular homolog of the retroviral v-Myc oncogene (53), little more than a year elapsed before recognizing that the former was commonly rearranged, amplified, and/or otherwise deregulated in human cancers, most notably Burkitt's lymphoma (54-62). Shortly thereafter, endogenous Myc was found to be responsive to various mitogenic and differentiation-promoting stimuli, with the first type tending to upregulate and the second tending to downregulate its expression. Deliberately overriding these behaviors tended to reverse these tendencies, thereby demonstrating that Myc served as an active participant rather than a passive bystander. It was also shown that elevated and deregulated Myc expression frequently accompanies tumor progression and that the overexpression of Myc, either alone or in combination with other oncoproteins, was potently transforming both in vitro and in vivo (63-88).

It was not until the mid-1980s, however, that the relationships between protooncogene expression, normal and neoplastic proliferation, and altered metabolism began to truly take shape and mold our current outlook. For example, the eventual classification of Myc as a so-called "immediate-early" gene in response to growth factor stimulation in fibroblasts $(65,78,80,81)$ led to the finding that the ectopic conditional expression of Myc alone was sufficient to promote an abortive G0 $\rightarrow$ S-phase transition (63). Shortly thereafter, studies in quiescent thymocytes and fibroblasts additionally showed that Myc induction following mitogenic stimulation was preceded by rapid and sequential changes in phosphoinositide metabolism, $\mathrm{Ca}^{2+}$ release, the activation of phospholipid-dependent kinase $\mathrm{C}$ and altered $\mathrm{Na}^{+} / \mathrm{H}^{+}$exchange $(89,90)$. Enforced Myc or Ras expression in log-phase Rat1 fibroblasts was also then found to stimulate glycolysis, which was further enhanced by the addition of the growth factor TGF- $\beta$ (91). Subsequently, differential screening of $\mathrm{cDNA}$ libraries prepared from quiescent and serum-stimulated Balb/3T3 murine fibroblasts identified a small number of transcripts that were induced within $12 \mathrm{~h}$ of applying this mitogenic stimulus (92). In addition to Myc, these encoded LDH and enolase, thus hinting at the idea that Myc might be involved in the regulation of metabolism, that specific genes within the glycolytic pathway might be important for initiating the biomass accretion necessary for growth and division, and that Myc might somehow be involved in the regulation of these genes. Being mindful of proper historical context, it is important to note that these studies preceded by over a year the initial reports that Myc was a DNA-binding transcription factor (93-96). Thus, the relationship between Myc and transcripts encoding metabolic enzymes remained enigmatic until this critical Myc function was unmasked. It is now known that nearly all genes encoding glycolytic enzymes are direct Myc targets and that the Warburg effect is at least partially under Myc control (97-99). Together, these findings underscore two of the three major themes mentioned in the preceding section: first, that the metabolic changes accompanying rapid normal and malignant proliferation utilize the same pathways as normal quiescent cells, although not always for the same reasons; and second, that malignant cells maintain or corrupt these pathways for the singular purpose of gaining a proliferative and/or survival advantage over their normal counterparts, or even their transformed but less metabolically adaptable relatives.

Over the next several years, it gradually emerged that one of Myc's principle functions, both in normal and cancer cells, was to regulate cell mass and, in doing so, to directly modulate the expression of genes involved in ribosomal biogenesis including ribosomal structural genes, tRNAs, rRNAs, and all three eukaryotic RNA polymerases that control the expression of these 
genes (100-109). The identification of these novel Myc targets was a satisfying observation as it began to shed light on how an oncoprotein could promote proliferation on the one hand while coordinating this with protein synthetic rates (or at least the protein synthetic machinery) and the doubling of cell mass that must precede division on the other (110). It also complemented earlier observations that transformed cells increase their uptake of both amino acids and the glucose analog 2-deoxy-glucose (2-DG) (91, 110). Yet even by this time and with these observations in hand, little attention was paid to the other metabolic changes needed to support the growth and proliferation of cancer cells. Not that they had been entirely ignored; indeed, there were hints as early as the mid-1950s that such changes were intimately associated with the increased proliferation of cancer cells including the eponymous Warburg effect mentioned earlier $(3,111,112)$.

\section{MYC AND THE REGULATION OF GLYCOLYSIS, OXPHOS, AND ENERGY BALANCE}

As emphasized above, Myc's pivotal role in the control of carbohydrate metabolism emerged gradually in the mid-late 1980s and early 1990s. However, it first required demonstrating that Myc is a sequence-specific DNA-binding transcription factor (92-95, $113,114)$, together with the subsequent development of highthroughput and unbiased methodologies to identify Myc-target genes (115-119). From among the earliest such attempts emerged one of the first direct Myc-target genes (120), namely, the " $\mathrm{A}$ " isoform of $\mathrm{LDH}$ (LDH-A), which, as noted above, had been previously identified, along with Myc itself, as being induced by serum in fibroblasts (92). Shim et al. and Lewis et al. subsequently demonstrated that Myc-mediated fibroblast transformation was attenuated following the genetic suppression of LDH-A, that these fibroblasts were highly susceptible to apoptotic death in the face of glucose deprivation and that LDH-A could cooperate with another Myc target, rcl, to transform fibroblasts (120-122). Rather than being directly transforming, however, it seems more likely that LDH's role is more related to the fact that the LDHmediated generation of lactate from pyruvate requires $\mathrm{NADH}$ as an electron donor and that the product of this reaction, $\mathrm{NAD}^{+}$, may then function as an electron acceptor to support more proximal glycolytic reactions (Figure 1). This co-dependency between glycolysis and lactate generation ensures that the former pathway can be efficiently maintained regardless of its rate, particularly when oxygen concentrations are low, the generation of lactate is high and glycolysis is the major ATP source. Further supporting the importance of this positive feedback loop was the subsequent observation that most glycolytic enzyme-encoding genes are regulated at some level by Myc (120, 123-127). Thus, the production and excretion of lactate, an otherwise energetically wasteful activity, is actually necessary to sustain the Warburg effect as it ensures the continuous generation of $\mathrm{NAD}^{+}$to serve as an electron acceptor during glucose oxidation. In the presence of oxygen, cytoplasmic $\mathrm{NAD}^{+}$may also be supplied via the glycerol-3-phosphate shuttle and the malate-aspartate shuttle in which reducing equivalents are transferred to the mitochondria in exchange for generating an oxidized cytoplasm to maintain glycolysis $(128,129)$. While these shuttles are likely to be less important under the hypoxic conditions that often prevail during tumor growth, they nonetheless allow for cross talk, cooperation, and coordination between glycolysis and OXPHOS in welloxygenated environments (130-132).

Warburg-type glycolysis, in conjunction with the abovementioned shuttles, couples the generation of reducing equivalents in the form of $\mathrm{NADH}$ with their indirect transfer into the mitochondrial matrix to drive the ETC and maintain membrane potential $(\Delta \Psi \mathrm{M})$ and the protomotive force that generates ATP via Complex V. The glycerol-3-phosphate and malate-aspartate shuttles thus provide sources of mitochondrial reducing equivalents independent of those generated by the TCA cycle when the supply of pyruvate-derived acetyl-CoA (AcCoA) might be compromised due to the diversion of glycolytic intermediates for anabolic purposes and/or the production of lactate. These shuttles also sustain mitochondrial NADH levels when TCA-generated substrates are consumed by other anabolic reactions, such as the synthesis of lipids and certain amino acids. Interestingly, rather than being transferred to Complex I or Complex II as occurs with TCA cycle-derived reducing equivalents, the NADH supplied by these shuttles is confined to the inner mitochondrial membrane and surrenders its electrons directly to Coenzyme Q and then to Complex III of the ETC (133). Such reducing equivalents, derived from glycolysis, thus provide an electron source that bypasses Complex I and Complex II and is under different regulatory supervision.

Glycolysis also indirectly generates reducing equivalents in the form of NADPH during the proximal steps of the PPP. NADPH is a source of cytoplasmic reducing equivalents that supports the reductive de novo synthesis of sterols and fatty acids, regenerating $\mathrm{NADP}^{+}$in the process and providing an energetic and self-sustaining link between the biosynthesis of pentose sugars and lipids $(134,135)$. Thus, high rates of glycolysis and the lactate generation made in response to oncogenic stimuli such as Myc ensure a well-balanced and oxygen-independent supply of cytoplasmically generated ATP, reducing equivalents, and critical anabolic precursors (Figure 1).

Increased glycolytic flux ensures a rich supply of substrates that can be redirected into energy-consuming anabolic pathways with sufficient amounts remaining to generate $\mathrm{AcCoA}$ and drive the TCA cycle. But precisely how this occurs and whether any control is exerted remains somewhat enigmatic. Do the glycolysis-linked pathways simply "drink from the fire hose" of glycolytic intermediates as they rush down the pathway, or are there mechanisms that specifically direct glycolytic intermediates into anabolic pathways at the expense of mitochondrial OXPHOS, aided by the law of mass action? Support for the latter notion comes with the observation that the expression of the two isoforms of pyruvate kinase (PK), PKM1, and PK2, is altered in some cancers. PKM1, which tends to predominate in normal tissues, is replaced by PKM2, which has a higher $K_{\mathrm{m}}$ for its substrate, PEP; the $K_{\mathrm{m}}$ is even further increased by posttranslational modification. The overall lessened PK activity serves to redirect PEP and other upstream glycolytic substrates away from energy-generating OXPHOS and into energy-consuming anabolic pathways (136-140). 


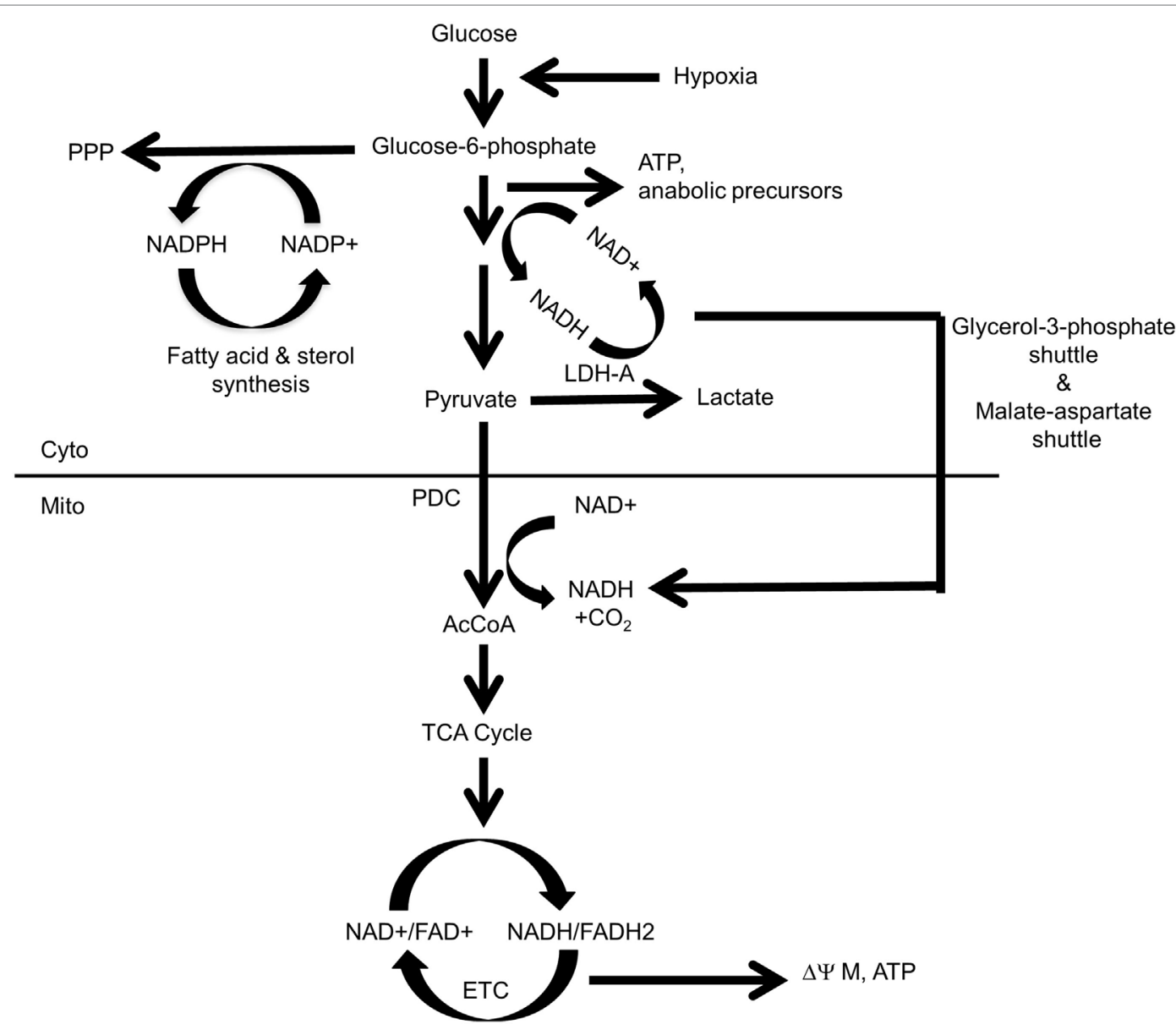

FIGURE 1 | Control and distribution of ATP and reducing equivalents derived from glycolysis and oxidative phosphorylation (OXPHOS). Under normal aerobic conditions, most glycolysis-derived pyruvate produced by quiescent or slowly growing cells is converted to acetyl-CoA (AcCoA) in the mitochondria, with little being converted into lactate. This provides the mitochondrial reducing equivalents, in the form of $\mathrm{NADH}$ and FADH2, to power the electron transport chain (ETC), to generate a proton gradient $(\triangle \Psi \mathrm{M})$ and to establish the protomotive force necessary to drive ATP generation via Complex V. Excess cytoplasmic reducing equivalents in the form of NADH may be transferred to the mitochondria via the glycerol-3-phosphate and malate-aspartate shuttles and can potentially support OXPHOS when AcCoA levels are low. During hypoxia, glucose uptake, glycolytically derived ATP synthesis, and the "A" isoform of LDH (LDH-A)-catalyzed conversion of pyruvate to lactate are accelerated due to an inability of the ETC to reduce molecular oxygen to water and generate TCA cycle-derived ATP. Most pyruvate will be converted to lactate, thereby generating more $\mathrm{NAD}^{+}$and sustaining anaerobic glycolysis. This positive feedback loop ensures a constant and balanced source of ATP as an energy source and the regeneration of $\mathrm{NAD}^{+}$to serve as an electron acceptor for continued glycolysis. By contrast, dividing cells have "divided loyalties" with regard to the disposition of glycolytic intermediates, with some being used to generate pyruvate and others being used as anabolic building blocks. Just as glycolysis and lactate production engage in a positive feedback loop to provide a balanced amount of NAD+ and NADH in support of one another's activity, the pentose phosphate pathway (PPP) and the biosynthesis of fatty acids and sterols, generate NADPH and NADP+, respectively, to support each others' pathways. The pyruvate dehydrogenase complex (PDC), which includes pyruvate dehydrogenase, is the key enzymatic complex that connects glycolysis to the TCA cycle. It catalyzes the conversion of the last product of glycolysis, pyruvate, to the entry-level substrate for the TCA cycle, AcCoA. In doing so, it contributes one-fourth of the NADH that is produced by a single round of the TCA cycle.

The PKM1 and PKM2 isoforms differ from one another as a result of mutually exclusive alternate mRNA splicing such that the PKM1 transcript encodes exon 9 but not exon 10 and PKM2 encodes exon 10 but not exon 9. The splicing decision is governed by at least three heterogeneous nuclear ribonucleoproteins, hnRNP1, hnRNP2, and hnRNP, which bind to intron regions flanking exon 9 and negatively regulate its splicing. Interestingly, hnRNP1 and hnRNP2 are positively regulated by Myc (141, 142). However, the switch to aerobic glycolysis, by whatever means, hardly signals an irreversible commitment; indeed, not only is the Warburg effect plastic but many tumors-even those of similar types are more dependent upon OXPHOS than glycolysis for their energy requirements and/or can rapidly balance these two processes to suit their needs (143). In addition to regulating glycolysis, Myc also exerts significant influence over mitochondrial structure and function. Initially relegated to a metabolic backwater following the realization that many cancer cells rely on the Warburg effect at the expense of OXPHOS, mitochondria do in fact play important roles in cancer metabolism $(144,145)$. Indeed, certain cancers remain highly reliant on OXPHOS as a means of energy production and show little predilection for Warburg-type metabolism (146). Analogous to glycolysis, 
however, both mitochondria and the energy producing pathways they encompass undergo significant structural and functional revisions in response to Myc deregulation.

Among the first studies to examine Myc's effect on mitochondrial structure and function were those of Li et al. (147). Utilizing P493-6 human B cells transfected with a tetracycline-inducible human Myc transgene, they showed that mitochondrial mass increased approximately twofold within $72 \mathrm{~h}$ of Myc induction, as measured by nonyl acridine orange staining, MitoTracker staining and mitochondrial DNA (mtDNA) content. Oxygen consumption increased to a similar extent thereby indicating a close relationship between structure and function. Transcriptional profiling also identified approximately 200 Myc-responsive genes encoding mitochondrial proteins, most of which were upregulated. Most notable among these was the transcript encoding Tfam, a nuclear-encoded mitochondrial transcription factor that also participates in mtDNA replication (148-150). The TFAM gene proximal promoter was also shown to contain a Myc-binding E-Box element. In serum-stimulated fibroblasts, endogenous Myc was shown to bind the same site (147). Although no functional studies were performed, it was assumed that this positive effect of Myc on mitochondrial biogenesis was accompanied by a parallel increase in TCA cycle activity and OXPHOS.

Elucidating the role of endogenous Myc in the regulation of metabolic pathways was hampered for quite some time by the lack of a suitable knockout model. This is because even shortterm Myc depletion in virtually all cell lines is accompanied by cell cycle arrest, apoptosis, or differentiation, thereby severely compromising long-term studies $(50,151,152)$. Similarly, whole body inactivation of the $m y c$ gene is an embryonic lethal (153). Thus, the generation of a $m y c^{-/-}$cell line from rat fibroblasts by Mateyak et al. in 1997 (154) provided a tremendous technical advance despite the fact that it remains unresolved as to how these cells survive and replicate.

Although viable, the $m y c^{-/-}$fibroblasts described by Mateyak et al. (154) are extremely abnormal. For example, they divide only once every $2-3$ days versus every $18-24 \mathrm{~h}$ for the $m y c^{+/+}$parental line, display an extremely flattened morphology and are highly contact inhibited. Cell cycle regulation is severely compromised at multiple points, with $m y c^{-/-}$cells showing a ca. 12 -fold reduction in the expression of CyclinD-Cdk4 and CyclinD-Cdk6 complexes during the $\mathrm{G}_{0} / \mathrm{G}_{1}$ transition and delayed activation of CyclinE-Cdk2 and CyclinA-Cdk2 complexes $(145,155)$. That most of these abnormalities can be rescued at least partially with retrovirally expressed Myc, the Myc homologs N-Myc and L-Myc, or the Myc-target genes MYCT1/MT-MC1, HMG-IY and SHMT $(156,157)$ indicates that the various phenotypes of $m y c^{-/-}$fibroblasts are directly related to $m y c$ gene inactivation and do not represent compensatory and Myc-independent growthenhancing adaptations.

The absence of Myc was also reflected in the mitochondrial structure and metabolism of these cells. Graves et al. (158) showed that, compared with $m y c^{+/+}$fibroblasts, the mitochondria of $m y c^{-/-}$fibroblasts were smaller, fewer in number, deficient in cristae and poorly interconnected. The activation of a Mycestrogen receptor fusion protein (MycER) by 4-hydroxytamoxifen (4OHT) complemented these defects, although, surprisingly, it required 4-5 weeks before maximal mitochondrial mass was restored. The extremely low $\Delta \Psi \mathrm{M}$ of these cells ( $\left.m y c^{-/-} \mathrm{MycER}\right)$ cells also increased in parallel over this same time period. This provided indirect evidence that Myc was likely controlling some aspect of the TCA cycle and/or the availability of reducing equivalents needed to drive the ETC. Following 4OHT's removal and the silencing of Myc, mitochondrial mass, $\Delta \Psi \mathrm{M}$ and interconnectivity returned to near the baseline levels of $m y c^{-/-}$cells over another prolonged period exceeding 10 days (158).

In addition to the above major structural defects, which confirmed and extended those of Li et al. (147), mitochondrial function was also severely compromised in $m y c^{-/-}$cells in a manner that mirrored their structural defects. For example, the basal oxygen consumption rate (OCR) of $m y c^{-/-}$cells was about half that of $m y c^{+/+}$cells and only $15 \%$ that of $m y c^{-/-}$cells stably reconstituted with a lentiviral vector that drove high level, constitutive Myc expression ( $m y c^{-/-}$Myc cells). The most prominent effect of Myc on OCR was seen in $m y c^{-/-}$Myc cells where the maximum respiratory capacity in response to the de-polarizing agent FCCP was $>20$ times higher than that of $m y c^{-/-}$cells and 6 times higher than that of $m y c^{+/+}$cells. Because Myc positively regulates virtually all glycolytic genes $(96,123,124,159)$, the basal rate of glycolysis in $m y c^{-/-}$cells was also about half that of $m y c^{+/+}$ cells and one-third that of $m y c^{-/-}$Myc cells (158).

Consistent with their markedly impaired OXPHOS and glycolysis, $m y c^{-/-}$cells showed a nearly $70 \%$ reduction in basal ATP levels, which normalized following Myc re-expression. In all three cell lines $\left(m y c^{-/-}, m y c^{+/+}\right.$, and $\left.m y c^{-/-} \mathrm{Myc}\right)$, exposure to 2-DG caused a more pronounced ATP depletion than did the inhibition of OXPHOS with rotenone. Taken together, these results suggested that at least half the energy in these cells was derived from glycolysis. Consistent with their ATP deficient state, $m y c^{-/}$cells expressed high levels of activated (phosphorylated) AMP-activated protein kinase (AMPK), a serine/threonine kinase that responds to ATP depletion (or more precisely to a high AMP:ATP ratio) by upregulating ATP-generating pathways and downregulating ATP-consuming pathways (160-162). However, since many of the energy-sparing and energy-generating effects of AMPK rely on the upregulation of Myc $(160,163,164)$, AMPK seems to be unable to achieve a state of true energy equilibrium in $m y c^{-/-}$cells, thereby leading to its constitutive activation in the face of a chronic energy deficit. The restoration of Myc in $m y c^{-/-}$ Myc cells did lead to AMPK dephosphorylation that correlated with the normalization of ATP levels (160).

The observation that $m y c^{+/+}$and $m y c^{-/-}$Myc cells contained identical ATP levels could not initially be reconciled with the finding that the latter cells had significantly higher rates of glycolysis and OXPHOS. This discrepancy was resolved by showing that the ATP half-life in the latter cells was nearly 50\% shorter (2.6 versus $3.6 \mathrm{~min}$ ) (158). This was consistent with the previous finding that $m y c^{-/-}$WT cells had significantly faster growth rates than $m y c^{+/+}$cells and thus likely utilized more ATP (165).

To further understand the role of endogenous Myc in maintaining basal rates of glycolysis and OXPHOS in transformed cells, Graves et al. (158) utilized the conditional, doxycyclineregulatable expression of a short hairpin RNA directed against Myc to silence the oncoprotein's expression in A549 human small 
cell lung cancer cells, which normally express high levels of Myc. Conforming to the findings in the above-discussed rat fibroblast studies, the knockdown of Myc was associated with marked growth inhibition, a flattened cellular morphology, reduced mitochondrial mass, and the collapse of $\Delta \Psi \mathrm{M}$.

Relative to $m y c^{+/+}$and $m y c^{-/-}$Myc cells, $m y c^{-/-}$cells demonstrated abnormalities in overall structure and function of the ETC (158). Among these were reduced amounts of the so-called "supercomplexes" (SCs) between Complexes I, III, and IV, which allow for more efficient electron transfer $(166,167)$. Consistent with their atrophic mitochondrial cristae, which are believed to serve as a platform for the formation and accretion of SCs (168, 169), $m y c^{-/-}$mitochondria also contained lower levels of Complex I, II, and III as well as both the monomeric and dimeric forms of Complex V ATPase $\left(\mathrm{V}_{\mathrm{m}}\right.$ and $\mathrm{V}_{\mathrm{d}}$, respectively) relative to $m y c^{+/+}$cells. In general, SC function in $m y c^{-/-}$cells, as measured by in situ enzymatic activity of individual complexes separated by non-denaturing blue native gel electrophoresis (BNGE), closely matched Coomassie Blue staining patterns. $m y c^{-/-}$fibroblast mitochondria also contained significant levels of an enzymatically inert complex (Complex "X") that was shown by mass spectroscopy to be comprised of multiple subunits from Complexes II-V. It was speculated that during periods of relative oxidative quiescence, Complex $\mathrm{X}$ functions as a reservoir for certain mitochondria proteins, which can be rapidly summoned and assembled into their respective ETC complexes in response to increased metabolic needs. This seems like a logical cellular strategy in that cells with depleted energy levels as a result of ETC dysfunction might be better served by utilizing preexisting ETC components for rapid assembly and resumption of ETC function rather than expending even more energy by synthesizing them anew. On the other hand, the surprisingly long time it takes to restore normal mitochondrial structure and function in $m y c^{-/-}$ cells (158) raises questions as to whether this is the true function of this complex.

Interestingly, $m y c^{-/-}$Myc cells showed only a partial normalization of ETC structure and function as measured by the above methods, despite their high-level Myc expression. Relative to $m y c^{+/+}$cells, $m y c^{-/-}$Myc cells contained only about half the levels of SCs, two-thirds the level Complex V monomers $\left(\mathrm{V}_{\mathrm{m}}\right)$ and $\sim 15 \%$ the level of Complex $\mathrm{V}$ dimers $\left(\mathrm{V}_{\mathrm{D}}\right)$ as measured by both enzymatic activity and BNGE. While both $V_{D}$ and $V_{M}$ possess ATP synthase activity, the dimer appears to be more important for dictating the shape of mitochondrial cristae (170). Because the high-level re-expression of Myc also greatly increased glycolysis, it was surmised that this failure to entirely normalize ETC structure and function was due to a combination of factors including structural changes to the mitochondria and their cristae, differences in the relative contribution of glycolysis and OXPHOS to the energy landscape, subtle nuances relating to the control of Myc protein expression, and differential cellular growth rates and their resulting anabolic requirements (158).

The normalization of mitochondrial morphology by the enforced re-expression of Myc in $m y c^{-/-}$Myc cells (158) suggested that Myc might influence mitochondrial fusion and/ or fission. The former process is regulated by the so-called "mitofusin" proteins such as Mfn1, Mfn2, and Opa1 whereas the latter process is regulated by the proteins Fis 1 and Drp/ Dlp (171-175). Fusion is believed to maximize mitochondrial energy production by allowing old and/or damaged organelles to be "rejuvenated" by combining their contents with those of younger ones, thereby extending their life span and functional integrity and capacity $(176,177)$. By contrast, fission provides a mechanism by which mitochondrial mass can be reduced during periods of relative metabolic quiescence or Warburg-type respiration or by which defective and/or aged mitochondria can be eliminated. Both fusion and fission can exert significant influence upon mitochondrial energy production and cell survival $(176,178,179)$.

Virtually, all the above mitochondrial fission and fusion proteins were expressed at higher levels in Myc replete cells relative to $m y c^{-1-}$ cells making it unclear how, as an integrated group, they affected mitochondrial biogenesis and, if so, which of the processes this favored. The question was answered by experiments in which 4OHT-treated $m y c^{-/-}$MycER cells were separately transfected with mitochondrially targeted green or red fluorescent proteins (GFP or RFP, respectively). Cells from the two populations were then mixed and fused by exposure to polyethylene glycol and the rate of $\mathrm{GFP}^{+}$and $\mathrm{RFP}^{+}$mitochondrial fusion into "yellow" merged organelles was quantified either in the continued presence of $4 \mathrm{OHT}$ or following its removal. Cells actively expressing Myc showed nearly twofold higher rates of mitochondrial fusion compared with cells in which Myc had been silenced for 2 days by removing $4 \mathrm{OHT}$. The faster rate of mitochondrial turnover in the former cells suggested that they were under constant pressure to maintain only the youngest and healthiest mitochondria to meet the increased metabolic needs of this energetically more demanding and faster growing population. Thus, along with affecting the levels of key mitochondrial transcription factors such as Tfam $(123,147)$, Myc also influences mitochondrial biogenesis and lifespan by modulating the levels of fission/fusion proteins.

Subsequent work demonstrated that alterations in mitochondrial structure and function can reciprocally impact the function of both endogenous and overexpressed Myc. In these studies, Sarin et al. (180) enforced the expression of the mitochondrial fission protein Drp/Dlp in Ratla-MycER cells, leading to a state of non-stop, fission-induced mitochondrial fragmentation and a pronounced reduction in overall mitochondrial size, mass and interconnectivity. Accompanying this was a nearly 15 -fold higher rate of mitochondrial fusion relative to control cells suggesting that Drp1/Dlp1-overexpressing cells constantly upregulate fusion in a futile compensatory attempt to offset their excessive Drp1/Dlp1-driven fission. Despite the fact that these cells expressed normal levels of Myc, their mitochondria were both structurally and functionally reminiscent of those from $m y c^{-1-}$ cells. Structurally, their ETC complexes were defective; BNGE revealed a $28 \%$ reduction Complex I, a $45 \%$ reduction in Complex V and a 38\% reduction in SCs. Furthermore, Complex "X," the proposed repository for certain ETC subunits in $m y c^{-/-}$ cells (158), now appeared. Thus, enforced and uncorrected mitochondrial hyper fission leads to a loss of mitochondrial structural integrity resembling that of $m y c^{-/-}$cells in the face of otherwise normal Myc levels. 
Further characterization of Drp1/Dlp1-overexpressing cells showed that, like $m y c^{-/-}$cells, they too had a critical energy shortage, with a $>80 \%$ reduction in ATP levels and impaired glycolysis and OXPHOS. This energy-depleted state, coupled with the failure to adequately compensate for it, was evidenced by a ca. $30 \%$ decrease in mean cell volume and a $>10$-fold increase in phosphoAMPK (180). Collectively, these findings suggested that the price for such energy-conserving processes was a reduction in energetically demanding biomass accumulation. Most likely as a result of their abnormal ETC structure and/or their ATP deficit, Drp1/Dlp1 overexpressing cells, like $m y c^{-/-}$cells, expressed higher levels of ROS than control cells $(181,182)$. No obvious growth differences between control and Drp1/Dlp1-overexpressing cells were observed under standard conditions although the latter were significantly more resistant to apoptosis in response to Myc overexpression or serum deprivation and this was supported by the less pronounced release of cytochrome $\mathrm{c}$ from mitochondria. Treatment with 5-amino-1-b-D-ribofuranosyl-imidazole-4-carboxamide, an AMP analog that activates AMPK and increases ATP pools $(161,162,183)$ doubled the ATP content of Drp1/Dlp1 overexpressing cells, normalized their size and increased their sensitivity to apoptotic stimuli (180). The prolonged survival of Drp1/Dlp1-overexpressing cells may reflect the fact that ATP depletion tends to protect against apoptosis, perhaps by inhibiting caspases 3 and 8 and Apaf-1, and that, in some circumstances AMPK activation can restore or promote apoptosis (184-188). Collectively, these results show that enforced mitochondrial fission driven by Drp1/Dlp1 can override Myc's role in maintaining normal mitochondrial integrity and adequate ATP levels. Whether this is due to a lack of response of mitochondria as a result of their inability to fuse in response to Myc (as seems likely) or another effect of Drp1/Dlp1 remains to be determined.

The above studies showed that, at least in proliferating fibroblasts propagated in vitro, where nutrient supplies and oxygen concentrations are high and non-rate-limiting, both glycolysis and OXPHOS are subject to positive regulation by endogenous Myc. Moreover, they establish that the overexpression of Myc, to the levels required to drive proliferation and transformation, continues to exert a simultaneous positive effect on both glycolysis and OXPHOS. The effects are quite heterogeneous, are both direct and indirect and involve changes in transcripts encoding glycolytic enzymes and mitochondrial structural and functional components. These studies show that the Warburg effect and OXPHOS are by no means mutually exclusive. Rather they are better viewed as being complementary, with neither one being entirely dispensable (Figure 2).

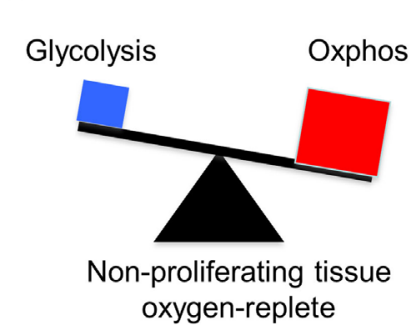

B

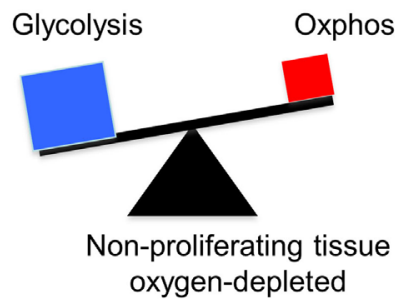

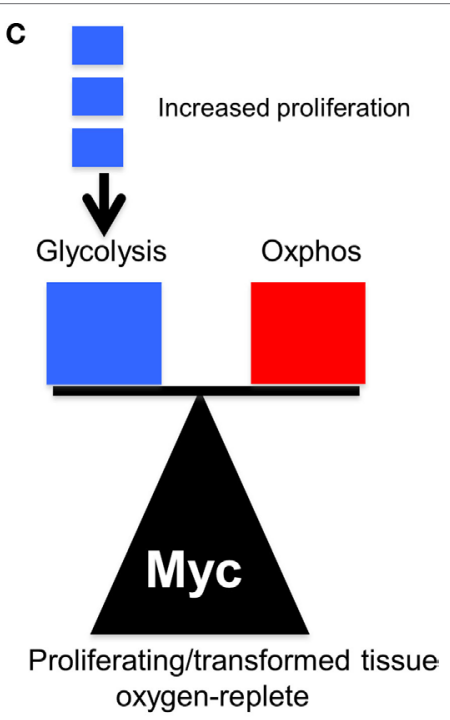

FIGURE 2 | The balance between glycolysis and oxidative phosphorylation (OXPHOS) in normal and tumor cells. The sizes of the triangles are meant to indicate the relative metabolic activity under each of the depicted conditions. (A) Under aerobic conditions, glucose in quiescent, non-proliferating cells is converted in a linear fashion into pyruvate, which is then consumed by the TCA cycle to produce the bulk of ATP (Figure 1). (B) Under hypoxic periods in these same cells, OXPHOS is no longer able to furnish ATP. Energy production then switches rapidly to glycolysis, which can temporarily maintain energy supplies. Both glucose uptake and glycolysis can be highly upregulated although at the expense of generating considerable amounts of lactate. (C) In well-oxygenated, rapidly proliferating tumor cells and normal cells, glycolysis and OXPHOS are both upregulated and balanced so as to provide for the most efficient production of ATP, the most rapid biomass accumulation and the most rapid rate of proliferation. The metabolic building blocks for these processes are derived from both the glycolytic pathway and the TCA cycle, thus explaining the need for each. Examples of the first include the diversion of glucose-6-phosphate into the pentose phosphate pathway to provide pentose sugars for nucleotide synthesis (Figure 1), the diversion of 3-phosphoglycerate for the synthesis of purine nucleotides and the diversion of phosphoenol pyruvate for the synthesis of tyrosine, tryptophan, and phenylalanine. Examples of the second include the transport of citrate into the cytoplasm for use in fatty acid and sterol biosynthesis and the diversion of oxaloacetate into the cytoplasm for conversion in aspartate, asparagine, and pyrimidine nucleotides. While the graphic here depicts an equal contribution by both glycolysis and OXPHOS, their relative contribution to overall metabolism can shift in response to proliferative rates (indicated by the small blue boxes), oxygen tension, and the supply of environmentally derived nutrients. In rare cancers, mutations in select TCA cycle genes can impart increased, and less reversible, reliance on aerobic glycolysis as a means of generating energy, thus confirming to Warburg's original explanation of his eponymous effect (41-43). 
The role of endogenous Myc in sustaining glycolysis and mitochondrial function has received additional support from studies in other cell types with several structurally and mechanistically distinct small molecule Myc inhibitors (189-191). HL60 promyelocytic cells exposed for only 2-5 days to these compounds dramatically reduced their ATP content, activated AMPK, accumulated neutral lipids and downregulated Myc as they underwent terminal myeloid differentiation. Because the manipulation of Mychad long been know to exert profound effects on the differentiation of hematopoietic and other cell types (68, $72,77,87,192$ ), Wang et al. repeated these experiments using two mechanistically distinct inhibitors of Complex I, metformin and rotenone (191). Decreased ATP, AMPK activation and myeloid differentiation were again noted, but Myc levels were unaffected. These studies supported the idea that ATP levels are a strong and Myc-independent determinant of differentiation, at least in myeloid cells (193). They further implied that a major role of Myc in differentiation is to maintain ATP levels, most likely with the purpose of allowing for the continued accumulation of biomass. This is also likely aided by Myc's ability to induce the expression of many genes involved in cell cycle progression $(101,194,195)$. Differentiation may therefore represent one possible means of maintaining viability in response to energy-depleted states.

In other studies using a transgenic mouse model of neuroblastoma driven by the highly related Myc homolog N-Myc, Zirath et al. (196) showed that the treatment of tumor-bearing animals with the small molecule Myc inhibitor 10058-F4 (197), which also binds to and distorts the structure of N-Myc (198), inhibited tumor growth and promoted tumor differentiation as evidenced by neurite outgrowth. It also caused the accumulation of high levels of intracellular neutral lipid (196).

Activated T-cells are among the most rapidly dividing metazoan cells. Following antigen stimulation, they accumulate biomass for approximately $24 \mathrm{~h}$ and then enter a phase of rapid proliferation and clonal expansion, with cell division occurring as frequently as every $4 \mathrm{~h}$ (199). It has long been known that this replicative phase is associated with markedly increased glycolysis and glutaminolysis although the precise pathways needed to effect this metabolic reprogramming remain ill defined (200-202). Wang et al. (203) investigated Myc's contribution to the biomass accretion and proliferative expansion following ex vivo stimulation of murine T-cells with anti-CD3 ${ }^{+}$anti-CD28. Immediately following their initial $24 \mathrm{~h}$ growth period, control cells entered the expected rapid proliferative phase during which time they were subject to metabolomic profiling using mass spectroscopy. Wang et al. (203) found that these cells accumulated metabolites during the initial growth phase and then activated glycolysis and directed glucose into the PPP. Concurrently, FAO declined as did the delivery of pyruvate into the TCA cycle. By contrast, OXPHOS and glutaminolysis increased, with a significant amount of the glutamine-associated carbon and nitrogen ultimately being incorporated into $\alpha$-ketoglutarate and nucleotides, respectively. This latter finding indicated that exogenous glutamine was directed along two distinct pathways, the first being the TCA cycle in which glutamine was converted to glutamate and then to $\alpha$-ketoglutarate and the second being the purine synthesis pathway in which both the N3 and N6 positions of the purine ring are derived from the glutamine amide moiety. Thus, not unlike the case of Myc-overexpressing fibroblasts discussed earlier (158), T-cell activation was accompanied by increases in both glycolysis and OXPHOS although the source of substrates for the latter pathway shifted from fatty acids and glucose to glutamine. Impaired proliferation was observed when the cells were deprived of either glucose or glutamine or when glycolysis and glutaminolysis, but not FAO, were blocked pharmacologically.

To investigate the molecular basis for the above-described metabolic reprogramming, Wang et al. (203) excised Myc from $m y c^{f l o x / f l o x} \mathrm{~T}$ cells following conditional activation of a 4OHTinducible CreER transgene and compared their ex vivo response to anti-CD3 ${ }^{+}$anti-CD28 activation to the above control mycflox/flox cells. They noted a severe impairment of both the initial mass accretion (growth) phase and the subsequent expansion phase. In vivo testing of these cells following their stimulation with staphylococcal enterotoxin B revealed a blunted response similar to that observed ex vivo, with a decrease in both the growth and activation phases. Metabolomic profiling showed that the accumulation of amino acids, nucleotides and lipids in these cells was

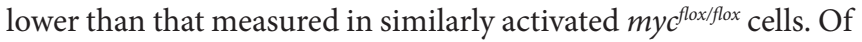
note was that $m y c^{-/-}$cells still activated both ERK and AKT pathways at levels commensurate with those seen in control myctlox/flox cells. This supported the idea that the observed effects were not a consequence of an inability to respond to signals upstream from Myc but rather to the lack of Myc itself. Further metabolomic inquiry showed that $m y c^{-1-} \mathrm{T}$ cells had impaired FAO and glucose flux during both the growth and proliferative phase, accumulated less lactate and directed less glucose-derived carbon into the PPP. Consistent with these findings, the induction of several glycolytic enzymes and glucose transporters were also suppressed as was glutaminolysis. The PKM2 isoform was also less highly induced in $m y c^{-/-}$T-cells.

\section{THE ROLE OF GLUTAMINOLYSIS IN METABOLIC REPROGRAMMING}

It has been known since the mid-1950s that both normal and transformed cells share a particular predilection for exogenous glutamine and sometimes even prefer it to glucose as an energygenerating substrate (204-207). Indeed, some tumors have such exaggerated demands for this amino acid that they can deplete host plasma glutamine levels despite its being the most abundant amino acid $(208,209)$. Recent evidence supports the idea that glycolysis and glutaminolysis cooperatively support high rates of cell proliferation $(210,211)$.

Glutaminolysis offers several advantages that explain its ability to complement and/or replace glucose as an energy source (Figure 3). First, it can be used directly for de novo protein synthesis as can the amino acids derived from it including glutamate, proline, histidine, alanine, aspartic acid, and arginine. Second, it may facilitate the uptake of other amino acids, thereby regulating and coordinating their availability for protein synthesis as well (212-214). Third, it serves as the starting point for the biosynthesis of purine nucleosides, thereby linking protein and nucleic acid synthesis. It is noteworthy that 


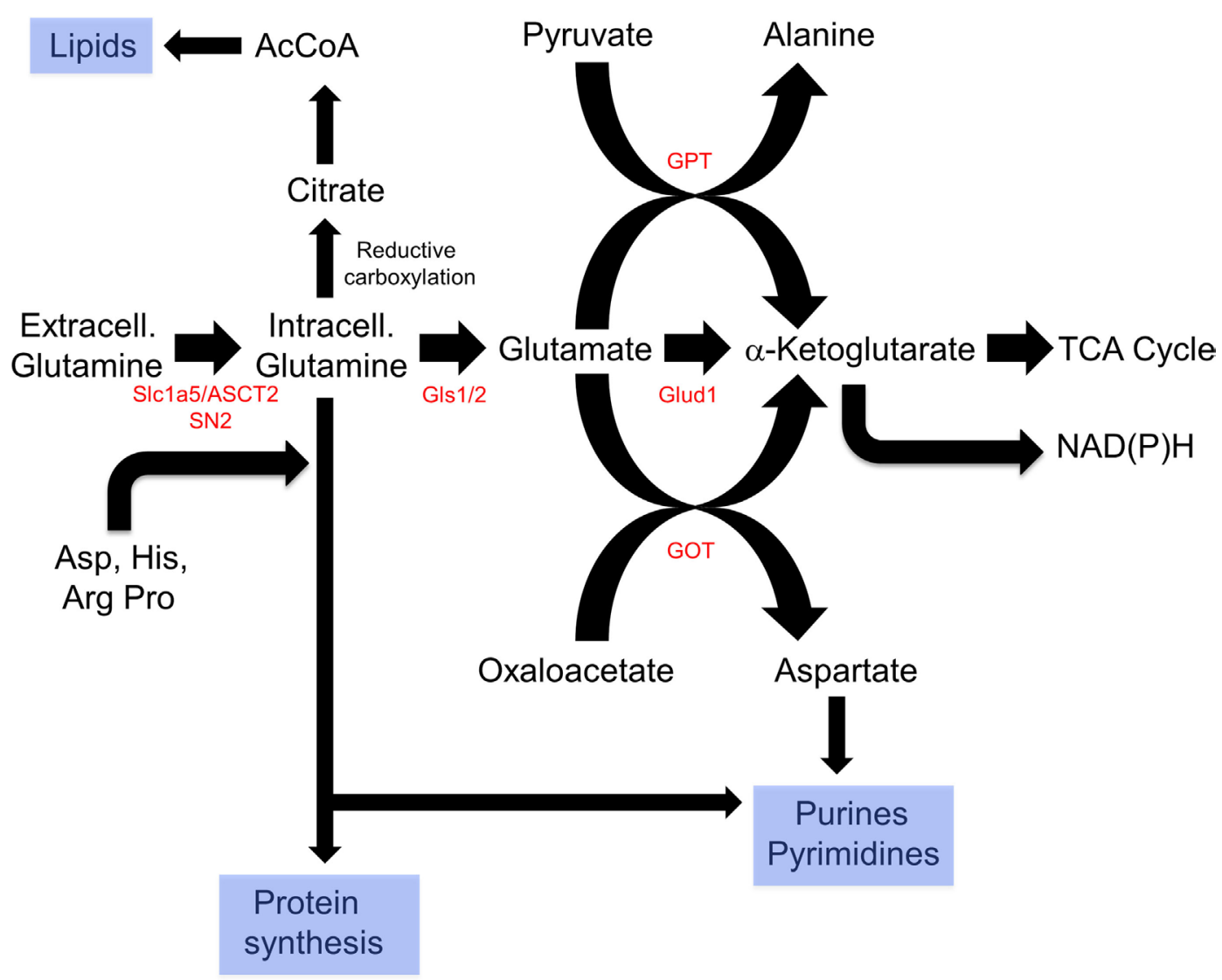

FIGURE 3 Reprogramming of glutamine metabolism by rapidly proliferating cells. Extracellular glutamine, along with several other amino acids, is delivered to the cytosol by the SLC1A5/ASCT2 or SN2 transporters (212-214). Together, these contribute to de novo protein biosynthesis, whereas aspartate is also used in purine and pyrimidine synthetic pathways. In addition, glutamine can undergo reductive carboxylation to supply citrate, which can be converted by ATP citrate lyase to supply cytosolic acetyl-CoA (AcCoA) for de novo lipid synthesis $(216,217)$. Finally, glutamine can be catalyzed by glutamine synthase 1 (Gls1)/2 and then to $\alpha$-ketoglutarate by the mitochondrial enzyme glutamine dehydrogenase generating a molecule of NADH (or NADPH) in a glycolysis-independent manner. $\alpha$ Ketoglutarate can also be furnished via the action of glutamine pyruvate transaminase (GPT) or glutamate oxaloacetate transaminase (GOT), which utilize pyruvate or oxaloacetate, respectively, in reactions that also yield alanine and aspartic acid. Taken together, glutaminolysis thus coordinates amino acid, lipid, and nucleoside biosynthesis while concurrently providing energy to support these processes and contributing to the anaplerotic substrate supply.

the NADPH derived from the diversion of glycolytic substrates into the PPP can also positively impact glutamine uptake and sustain reactions involved in lipid synthesis $(215,216)$. Fourth, the glutamate dehydrogenase-mediated conversion of glutamate to $\alpha$-ketoglutarate generates an additional molecule of NADH. This, together with the NADH generated by the $\alpha$-ketoglutarate dehydrogenase and malate dehydrogenase reactions and the $\mathrm{FADH} 2$ generated by the $\mathrm{SDH}$ reaction, ensures that nearly normal levels of reducing equivalents can be supplied in a manner that is independent of AcCoA, glycolysis and FAO. Fifth, glutamine-derived $\alpha$-ketoglutarate can also participate in a reverse carboxylation reaction to furnish citrate for the generation of cytoplasmic AcCoA for use in de novo fatty acid and cholesterol biosynthesis $(216,217)$. Finally, during periods of oxidative stress as commonly occur in many tumors, high levels of ROS can inhibit the aconitase-catalyzed conversion of citrate to isocitrate, thus limiting the supply of glycolytically derived $\alpha$-ketoglutarate. Glutaminolysis provides a means of overcoming metabolic roadblocks such as this and thereby ensuring a more stable and consistent supply of $\alpha$-ketoglutarate and the downstream reducing equivalents derived from it $(215,218)$.

Given the central role of glutaminolysis for sustaining cellular proliferation, coupled with a previous finding that the apoptosis mediated by the absence of glutamine is Myc dependent (219), it was not surprising that Myc regulates this process at several levels. Wise et al. (220) first reported that glioma cells consumed large amounts of glutamine to drive OXPHOS and that the shRNAmediated suppression of Myc reduced glutamine consumption. They further observed that glioma cells were unable to survive in glutamine-deficient medium, even when supplied with glucose, and that the cell-permeable $\alpha$-ketoglutarate analog dimethyl- $\alpha$ ketoglutarate could substitute for glutamine, thereby providing strong evidence that the shunting of exogenous glutamine into the TCA cycle was directly responsible its effect on survival. Moreover, they showed that glycolysis and glutaminolysis, while both Myc regulated, were under distinct forms of control by virtue of the fact that PI3K/Akt signaling regulated the former but not the latter. Myc was subsequently found to bind selectively to 
E-box-containing promoter regions of the glutamine transporter genes SLC1A5/ASCT2 and SN2. shRNA-mediated suppression of Myc resulted in lowered expression of both transporters' transcripts and reduced glutamine consumption. Finally, the enforced transient expression of high levels of Myc in MEFs upregulated SLCA15/ASCT2 as well as glutamine synthase 1 (Gls1) and diverted glucose away from its oxidative metabolism by the TCA cycle and into the Warburg-type aerobic glycolysis instead. The mechanism by which Myc upregulated Gls1 appeared to involve increased transcription and/or stabilization of its mRNA.

Gao et al. (221) extended these results by showing that the levels of Gls1 protein in P-493 B cells and PC3 prostate cancer cells varied in direct proportion to the degree of Myc expression. However, and in contrast to Wise et al. (220), this was not true for Gls1 transcript levels leading the investigators to eventually determine that Myc regulated Gls1 at the posttranscriptional level by inhibiting the expression of two microRNAs, miR23a and miR23b (miR23a/b). Both miRNAs were noted to have homology to potential "seed" binding sequences in the Gls1 mRNA $3^{\prime}$-untranslated ( $\left.3^{\prime} \mathrm{UT}\right)$ region. A luciferase reporter vector containing the Gls1 3' UTR was shown to be responsive to these miRNAs. Thus, the Myc-mediated upregulation of Gls1 is indirect by virtue of its inhibition of at least two miRNAs, which inhibit Gls1 mRNA translation.

In a variation of the above theme, Qing et al. (222), extended these findings to include several human neuroblastoma cell lines and 80 primary human neuroblastomas with varying degrees of $\mathrm{N}$-Myc overexpression. As with the studies of Wise et al. and Gao et al. (221), they found that the cell lines underwent apoptosis in an N-Myc-dependent manner when deprived of glutamine. They also found higher levels of expression of Gls2 (but not Gls1), glutamate oxaloacetate transaminase (GOT2), SLCA15/ASCT2 and several other amino acid transporters that correlated with N-Myc expression levels. Apoptosis in cell lines in response to glutamine deprivation could also be inhibited or delayed by providing the cell-permeable TCA substrate dimethyl $\alpha$-ketoglutarate in place of glutamine.

Pérez-Escuredo et al. (211) showed that the uptake of ${ }^{3} \mathrm{H}$-glutamine and its utilization by highly oxidative cervical cancer cells was enhanced by lactate, which also accelerated tumor growth. They also showed that Matrigel-embedded tumor cells grown subcutaneously in immunocompromised nu/nu mice in the presence of high local concentrations of extracellular lactate upregulated Slca1A5/ASCT2 and Gls1 at the protein level. shRNA-mediated knockdown of the lactate transporter MCT1 abolished these effects indicating that actual transport of extracellular lactate was mediating the effects on glutaminolysis. The upregulation of Slca1A5/ASCT2 and Gls1 appeared to be mediated by Myc, whose levels were significantly increased by as little as a 6-h exposure to lactate. Further investigation found that the conversion of lactate to pyruvate blocked the activity of prolyl hydroxylases, which are negative regulators of hypoxia-inducible factors (HIFs) $1 \alpha$ and $2 \alpha$ (223). It was suggested that HIF- $2 \alpha$ stabilizes Myc via its intranuclear binding to Myc-Max heterodimers (224) and indeed, this tripartite interaction was observed in co-immunoprecipitation experiments. Furthermore, the silencing of HIF- $2 \alpha$ abolished the upregulation of Myc, Slc1A5/
ASCT2 and Gls1. Although HIF-1 $\alpha$ was not shown to interact with Myc or Max, it is known to collaborate with Myc to induce the expression of glycolytic genes, thus potentially contributing to the intracellular lactate burden and further stabilizing Myc (224). These effects may have been further aided by the stabilization of HIF- $1 \alpha$ by Myc itself (225).

Wang et al. (203) also examined glutamine dependency in the previously mentioned model of normal T-cell activation discussed earlier. They determined that glutamine deprivation resulted in impaired T-cell activation as well as decreased lipid and protein biosynthesis and led to an eventual $\mathrm{G}_{0} / \mathrm{G}_{1}$ arrest without affecting viability.

Although the Warburg effect and glutaminolysis are typically associated with high levels of proliferation $(1,2,5,226)$, they have also been observed in response to hypertrophy in otherwise non-dividing cells. Piao et al. (227), showed that the heart, which relies primarily on glycolysis and FAO for energy, reverts to using glutminolysis and also increases glucose utilization when subject to conditions that induce hypertrophy. Using two different models of right ventricular hypertrophy, they found variable degrees of Myc induction and increased expression of glutamine receptors SLC1A5/ASCT2 and Slc7A5 as well as increases in the mRNAs encoding the Glut1 glucose transporter and hexokinase (HK) 1. Consistent with the former of these findings, the investigators also noted increased ${ }^{14} \mathrm{CO}_{2}$ production derived from ${ }^{14} \mathrm{C}$-labeled glutamine. In response to the glutamine antagonist 6-diazo-5-oxo-L-norleucine a decrease in glutaminolysis was noted and was associated with a compensatory increase in glucose oxidation and elevated cardiac output. These studies strongly implicate glutaminolysis as being directly involved in the biomass accumulation that accompanies active proliferation but not in proliferation per se.

\section{DISTINCT IN VIVO METABOLIC ROLES FOR MYC: NOT ALWAYS THE SAME FUNCTION IN NORMAL AND NEOPLASTIC TISSUES}

Myc's unequivocal role in integrating normal mass accretion and proliferative signals with altered metabolism in fibroblasts, myeloid cells, T-cells, and other cell types in vitro as discussed earlier contrasts sharply with recent studies in hepatocytes where Myc was found to be entirely dispensable for the long-term regeneration of normal liver parenchyma (228). Several previous studies had indicated that mice with a conditional, hepatocytespecific knockout of the $m y c$ gene could regenerate hepatic mass following two-thirds partial hepatectomy (PH) (229-232). Less clear was whether this was achieved as rapidly as occurred in control livers. To some extent, this uncertainty was the consequence of different groups having used different and mostly indirect techniques to measure hepatocyte proliferation and liver regeneration. Further compounding this was the fact that the $\mathrm{PH}$ model is a relatively crude and suboptimal way to measure longterm regenerative potential given that the average hepatocyte must divide only about 1.6 times to replace the resected liver mass and that the entire regenerative process is complete within 
$7-10$ days (233). Moreover, as many as $30-40 \%$ of the hepatocytes in the regenerating liver remnant remain quiescent following $\mathrm{PH}$, and about the same amount of "regeneration" can be attributed to hypertrophy rather than actual cell division $(234,235)$. Thus, none of these reports actually addressed the question of whether Myc was necessary to support sustained, long-term hepatocyte proliferation as might occur during the course of normal hepatocyte turnover or repair from chronic injury, both of which are processes of much longer duration (234). It further left open the questions of whether subtle but nonetheless significant differences in regeneration rates might have escaped detection using the $\mathrm{PH}$ model and what, in fact, was actually being measured in these other reports.

Edmunds et al. (228) addressed all of these issues by capitalizing on an elegant, robust, and sensitive murine model of Type I hereditary tyrosinemia $(236,237)$. In these mice, as in humans, inactivation of the fumarylacetoacetate hydrolase (FAH) gene, which encodes the final enzyme in the pathway for tyrosine catabolism, leads to the accumulation of toxic levels of the upstream tyrosine catabolites maleylacetoacetate and fumarylacetoacetate, eventually causing hepatocyte death, fibrosis, and hepatic failure (238). This ultimately fatal outcome can be blocked with the drug 2-(2-nitro-4-trifluoromethylbenzoyl)-1,3-cyclohexanedione (Nitisinone or NTBC), a reversible inhibitor of the enzyme 4-hydroxyphenylpyruvate dioxygenase (HPPD) (239). HPPD is a more proximal enzyme in the pathway and converts the first tyrosine catabolite 4-hydroxyphenylpyruvate to homogenistate. In this way, $\mathrm{fah}^{-/-}$mice can be maintained in a healthy state simply by providing NTBC in their drinking water and thereby blocking tyrosine catabolism and the accumulation of the deleterious metabolites.

$\mathrm{Fah}^{-/-}$mice can also be cured by the intrasplenic injection of as few as $10^{5} \mathrm{fah}^{+/+}$hepatocytes followed by the intermittent discontinuation and resumption of $\operatorname{NTBC}(236,237)$. Animals initially lose weight as they accumulate the toxic tyrosine catabolites. However, as endogenous $f a h^{-/-}$hepatocytes are gradually replaced by the $f a h^{+/+}$donor population over 4-5 months, the recipient mice are eventually rendered NTBC-free and their livers are comprised of 50-80\% donor hepatocytes $(228,236,237,240)$. As a way of monitoring hepatocyte proliferative potential, this model offers several advantages over PH. First, because the donor cells must divide 50- to 100 -fold during recipient liver repopulation, they undergo many more population doublings than do post-PH hepatocytes, thereby providing a more demanding and long-term replicative challenge. Second, donor hepatocytes from different sources can be used in "competitive" repopulation assays, analogous to those used for decades in bone marrow transplantation studies $(241,242)$. Provided that the recipient and donor populations can be distinguished, the ultimate contribution of each to the steady-state transplanted liver can be assessed with exquisite precision and even quite small deviations from the input donor ratios can be easily quantified $(228,240)$. Third, if so desired, the input ratio of the competing donor populations can be varied to reveal even more dramatic differences in regenerative potential. Finally, because the competing donor populations replicate in identical environments, differences in regeneration rates can be ascertained with many fewer animals than are required with $\mathrm{PH}$-based experiments.
Edmunds et al. (228) exploited the FAH model to assess the regenerative capacities of mixed $\mathrm{fah}^{+/+}$populations of $m y \mathrm{c}^{+/+}$ and $m y c^{-/-}$hepatocytes. Surprisingly, the ratio of the two donor hepatocyte populations recovered from the fully reconstituted recipient livers more than 4 months after their co-transplantation was identical to that of the input donor populations. Thus, even under the most demanding of circumstances, Myc's absence did not impair the long-term regenerative potential of hepatocytes in this particular model.

In addition to being at odds with the above-discussed role for Myc in the proliferation of fibroblasts and T-cells and numerous other cell types $(154,158,191,196,203)$, these results also differ from studies in Drosophila and some cancer lines showing that cells expressing higher levels of Myc tend to outcompete those with low levels (243-245). Similarly, the conditional deletion of $m y c$ or its dominant-negative inhibition in intestinal crypt cells or bone marrow cells is associated with severe proliferative defects although these may be ameliorated over time (49, 246-248). Thus, the elimination of endogenous Myc seems to have highly variable and tissue-specific effects, with liver representing an atypical although perhaps not unique example.

Ultimately, while the metabolic consequences of endogenous Myc loss are tissue specific and variable, it seems reasonable to conclude that, in most cases, Myc is responsible for maintaining context-appropriate levels of ATP and anabolic substrates by regulating the uptake and oxidation of nutrients that furnish glycolysis and the TCA cycle. In Myc's absence, as noted above, many tissue types appear to adapt to the associated nutrient and energy deficits via various strategies that include variable reductions in cell mass, proliferative rate and anabolic activity $(49,158,180,228,249)$. Interestingly, while Edmunds et al. (228) did not observe any significant differences in cell size, ATP levels or AMPK phosphorylation in the livers of mice following transplantation with $m y c^{+/+}$or $m y c^{-/-}$hepatocytes, these studies were performed on hepatocytes that had already re-populated the liver and reached a non-proliferating equilibrium state. It is certainly possible that more profound energy deficits might have been observed had the actual proliferating population been assessed at an earlier time following transplant. Nonetheless, these studies clearly demonstrated that $m y c^{-/-}$hepatocytes remain as fully capable as their wild-type counterparts at contributing to the long-term repopulation of the liver irrespective of whatever defects they may harbor.

Although $m \mathrm{yc}^{-/-}$hepatocytes demonstrated no obvious proliferative impairment in the above-described repopulation assay, they nevertheless showed several abnormalities that were evident even prior to transplantation (228). First, despite body weights identical to those of $m y c^{+/+}$mice, juvenile mice with hepatocyte-specific deletion of $m y c$ had smaller livers, consistent with a previous observation that myc hypomorph mice tend to have smaller numbers of otherwise normal-sized cells in some organs, including liver $(249,250)$. At first glance, this would seem to be inconsistent with fact that $m y c^{+/+}$and $m y c^{-/-}$hepatocytes competed equally in repopulation studies (228). However, it is possible that the requirements for $\mathrm{Myc}$ in the developing liver versus the fully developed liver are different. There may thus exist a phase early in development, but not beyond, during which Myc is required for hepatocyte expansion. Alternatively, the smaller 
size of $m y c^{-/-}$livers may more reflect an unappreciated role of Myc in regulating organ size $(251,252)$ than in limiting the proliferative potential of its individual constituent cells, which is what is measured in hepatocyte transplant studies.

In contrast to the above findings, adult $m y c^{-/-}$livers actually weighed more than $m y c^{+/+}$livers. The former possessed a significantly higher neutral lipid and triglyceride content, which likely accounted for their increased mass (228). This implied either that $m y c^{-/-}$livers take up and store greater amounts of these lipids and/or utilize less of them. Arguing against the latter point was the finding that $m y c^{-/-}$livers showed variable but significant increases in FAO. This suggested that, in the absence of Myc, hepatocytes both take up and utilize more fatty acids, with the former process outpacing the latter, eventually culminating in an increased storage pool, not unlike that seen in $m y c^{-/-}$fibroblasts or following short-term pharmacologic Myc or N-Myc inhibition in other cell types $(191,196,228)$.

Edmunds et al. (228) studied the structure and function of isolated mitochondria from $m y c^{+/+}$and $m y c^{-/-}$livers using BNGE and noted no obvious differences in the stoichiometries of the protein subunits of ETC Complexes I-IV or the ATP synthase (Complex V). Mass spectroscopic quantification of over 400 mitochondrial proteins, including all 93 subunits of the ETC, also showed no significant quantitative differences between the two groups. However, Complex I and Complex II activities were modestly but significantly reduced in mitochondria from $m y c^{-/-}$ livers in response to ADP and succinate whereas the activity of Complex V was increased by about the same amount. Coupled with the finding that ATP levels in $m y c^{+/+}$and $m y c^{-/-}$livers were comparable, this suggested that the loss in ETC function in $m y c^{-/-}$ livers was compensated for by a more efficient generation of ATP via Complex $\mathrm{V}$ and/or by the more inherently efficient process of FAO (253).

Collectively, these findings suggest a form of metabolic reprogramming by the $m y c^{-/-}$liver only partially resembling that seen in $m y c^{-/-}$fibroblasts, which may reflect the different tissues under consideration as well as their different proliferative rates. For example, ATP and AcCoA levels were markedly diminished in $m y c^{-1-}$ fibroblasts but were maintained at normal levels in $m y c^{-/-}$livers $(158,228)$ (Figure 4$)$. This appears to have been due to the employment of FAO as an alternative energy source by hepatocytes as well as to an increase in neutral lipid accumulation that has been previously reported in $m y c^{-/-}$fibroblasts, in hematopoietic cells following short-term inhibition of Myc, and in neuroblastomas following treatment with small molecule Myc inhibitors $(158,191,196)$. The neutral lipid accumulation by $m y c^{-/-}$hepatocytes was even more striking following their transplantation into $\mathrm{fah}^{-/-}$recipient mice. Oil Red $\mathrm{O}$ staining of fully reconstituted livers confirmed their significantly higher triglyceride content as well as larger and more numerous neutral lipid droplets (228). Indeed, the lipid within these livers was so abundant that much of it was extracellular. This was likely responsible for the significant inflammatory cell infiltrate that was observed as well as for the upregulation of numerous transcripts involved in acute and chronic inflammation, leukocyte signaling and fibrosis. Immunohistochemical staining for 4-hydroxynonenal, a by-product of ROS-mediated lipid peroxidation, was also detected as was evidence for dysregulated mitochondrial structure and function as previously reported in mice maintained on high fat diets (254-256). Other findings included the downregulation of 19 of the 44 transcripts encoding subunits of Complex I and seven of the 20 transcripts encoding subunits of Complex V. In the latter group, 10 of the remaining 13 transcripts were upregulated. Taken together, these studies suggested that the loss of Myc expression in resting hepatocytes is initially associated with the gradual accumulation of neutral lipid, not unlike that seen in non-alcoholic fatty liver disease (NAFLD) in association with ETC dysfunction $(257,258)$. When coupled with the metabolic stress imposed by regeneration-associated proliferation and chronic inflammation, this progressed to a phenotype closely resembling non-alcoholic steatohepatitis (NASH), a long-term consequence of NAFLD that is associated with high levels of oxidative stress, inflammation, fibrosis and eventual hepatic failure $(257,259)$. It is tempting to speculate that the loss of Myc in these hepatocytes, particularly during times of proliferation and high energy demand, leads to an attenuated glycolytic response and the dysregulation of mitochondrial structure and function. The resulting energy depletion and mitochondrial stress is accompanied by an increased reliance on FAO coupled with unbalanced fatty acid uptake and storage, intracellular ROS generation, inflammation, and long-term parenchymal damage that mimics NAFLD and NASH (228).

The above findings do not provide simple explanations for how endogenous Myc affects metabolism during normal growth. They do suggest, however, that these changes occur at multiple levels and that the compensation by $m y c^{-/-}$hepatocytes ultimately affects neither ATP generation, AcCoA levels nor proliferation. It remains to be determined precisely how ATP levels in $m y c^{-/-}$livers are maintained but it appears to be dependent on several different pathways including an increased efficiency of ATP production as suggested by the Complex V assays and the provision of alternate sources of AcCoA mainly from enhanced FAO. An alternative source might originate with increased glutaminolysis, which could conceivable circumvent the need to rely on glycolysis- or FAO-derived AcCoA by providing reducing equivalents in the form of both $\mathrm{NADH}$ and FADH2. Whatever the cumulative corrective mechanisms are that help to normalize hepatocyte energy generation and proliferative function, they come at considerable metabolic cost in the form of increasingly severe lipid storage and utilization defects.

Metabolic changes have also been studied in $m y c^{-/-}$hepatocytes in response to oncogenic signaling following the induction of hepatoblastoma ( $\mathrm{HB})$. HB is the most common pediatric liver cancer, almost invariably arising in children under the age of 3 years and is associated with somatic mutations of the $\beta$-catenin gene in $>80 \%$ of cases $(260,261)$. A useful mouse model of $\mathrm{HB}$ has recently been described in which tumors arise with nearly $100 \%$ penetrance following the hydrodynamic tail vein injection-mediated delivery of "Sleeping Beauty" plasmids $(262,263)$ encoding patient-derived mutant forms of $\beta$-catenin and yes-associated protein (YAP) (264-266). A major transcriptional target for $\beta$-catenin is Myc (267) and, not unexpectedly, Myc is among the most highly upregulated genes in HBs (Monga and Prochownik, unpublished data). 


\section{A}

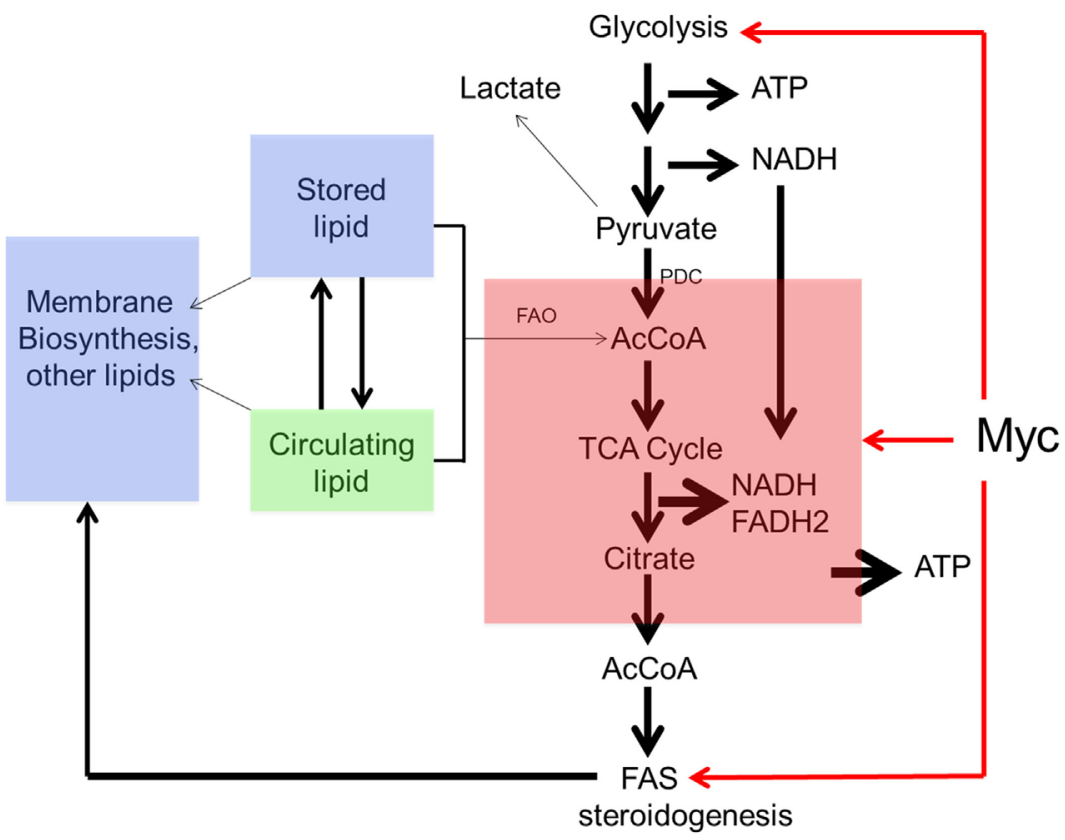

B

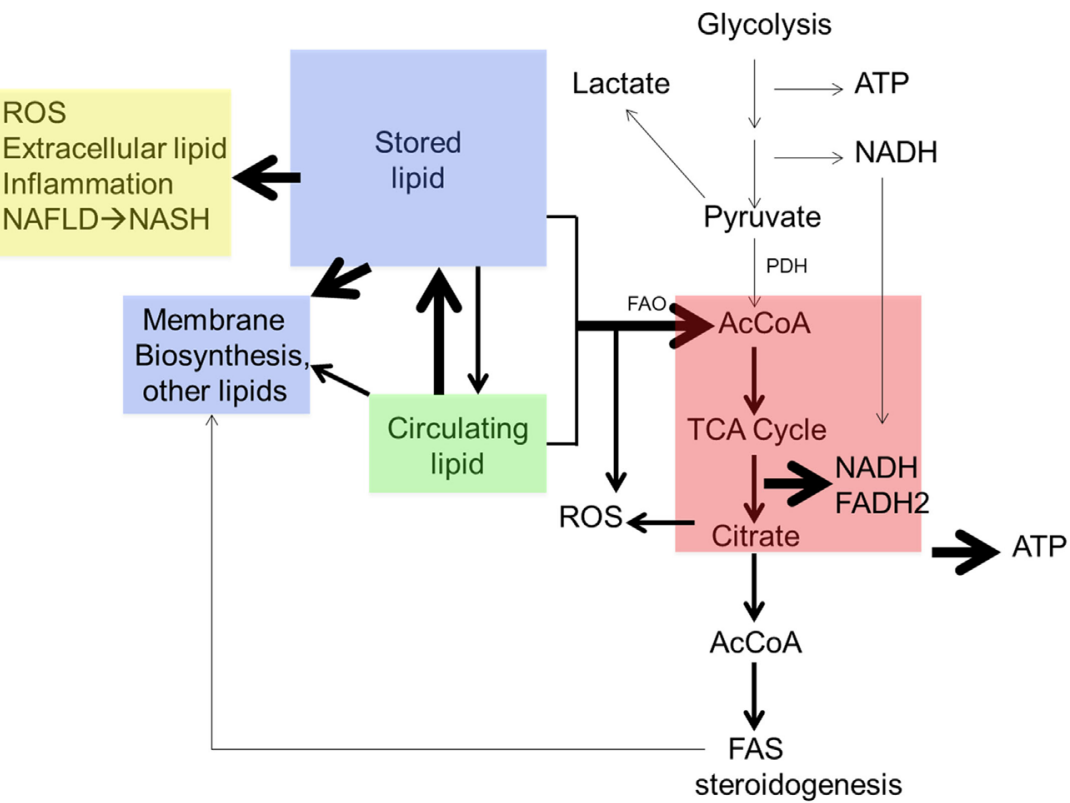

FIGURE 4 | Regulation of neutral lipid accumulation in $m y c^{-/-}$hepatocytes is both Myc dependent and Myc independent. (A) In myc ${ }^{+/+}$hepatocytes, the pathways indicated by red arrows are regulated both by Myc and Myc-independent factors. Stored lipid and circulating lipid are maintained in equilibrium. Stored lipid contributes minimally to energy generation (via FAO) or the synthesis of new membranes or other lipids when ATP and acetyl-CoA (AcCoA) are derived via glycolysis. Under these conditions, lipids such as fatty acids and sterols are largely synthesized from cytoplasmic AcCoA that originates from TCA cycle-derived citrate. (B) In myc ${ }^{-/-}$hepatocytes, basal rates of glycolysis, oxidative phosphorylation, and fatty acid synthesis are depressed thereby allowing for a compensatory increase in FAO. This allows basal levels of ATP and AcCoA to be sustained to meet energetic needs. New membrane synthesis thus becomes more reliant upon the uptake of exogenous lipids, which accumulate in the form of neutral lipids, leading to mitochondrial dysfunction and reactive oxygen species (ROS) generation (254-256). Additional ROS are generated as a result of the accumulation of intracellular and extracellular neutral lipid (257-259).

Given that Myc plays no role in normal hepatocyte repopulation as discussed earlier (228), it was of interest to determine whether Myc is needed to support the more rapid growth and increased metabolic demands of HBs. Indeed, Wang et al.
(125) found that, although tumors arose in $m y c^{-/-}$livers at the same frequency as they did in $m y c^{+/+}$livers, their growth rates were significantly impaired. Thus, while Myc was dispensable for normal hepatocyte proliferation and for the induction of 
HBs, it was clearly required for determining the rate of tumor growth $(125,228)$.

To understand the basis for Myc's selective role in HB proliferation (228), the metabolic properties of $m y c^{+/+}$and $m y c^{-/-} \mathrm{HBs}$ were compared. An initial assessment of mitochondrial function showed both types of HBs had lower OCRs and Complex II activity compared with corresponding livers. However, less suppression of these activities was seen in $m y c^{-/-} \mathrm{HBs}$. It is likely that this reflected their slower growth rates and thus a reduced tendency to rely on Warburg-type aerobic glycolysis for energy generation. Consistent with this, glycolytic transcripts as a group were upregulated in $m y c^{+/+} \mathrm{HBs}$ to a significantly greater extent than they were in $m y c^{-/-}$HBs (11.2-fold versus 8.9-fold, $P<0.0004)$. The presumptive lower glycolytic rate of the latter likely accounted for their lower AcCoA levels. Despite these differences, both tumor types showed elevated levels of ATP and a downregulation of phosphoAMPK relative to their respective livers. This suggested that, despite differences in their metabolic activities, the slower growth rates of $m y c^{-/-} \mathrm{HBs}$ were not the result of any obvious energy deficit. On the other hand, it is conceivable that $m y c^{-/-}$HBs were energetically constrained and that they maintained a rate of growth that was compatible with these limitations while still allowing normal levels of ATP to be maintained. The presumptive reduced rate of glycolysis by $m y c^{-/-}$ HBs may also have restrained the supply of anabolic precursors necessary for sustaining rapid tumor growth. In addition, these tumors were also less able than $m y c^{+/+}$tumors to upregulate the group of transcripts encoding the $\sim 80$ ribosomal protein genes (3.6-fold versus 5.2-fold, $P<10^{-4}$ ) (125). Thus, rather than being severely deprived of energy, as in the case for $m y c^{-/-}$fibroblasts, $m y c^{-/-}$HBs may instead be deprived of anabolic precursors and the ability to increase protein synthesis rates, despite adequate energy supplies. Protein synthesis rates and ribosomal protein content are known to be rate-limiting factors in the growth of many cancers $(108,268)$.

In further pursuit of an explanation for the overall downregulation of OXPHOS by tumors, Edmunds et al. (228) quantified mtDNA using qPCR to amplify two distinct regions of the mitochondrial genome. They documented a $\sim 60-80 \%$ reduced mitochondrial mass in both $m y c^{+/+}$and $m y c^{-/-}$tumors, thus providing a structural explanation for the Warburg effect. Results published at about the same time by Reznick et al. (269) showed a similar loss of mtDNA from a wide variety of human cancers whose genomic data had been compiled in The Cancer Genome Atlas (https://cancergenome.nih.gov).

In HBs arising in $m y c^{+/+}$and $m y c^{-/-}$livers, eight of the 14 most deregulated pathways identified by Ingenuity Pathway Analysis involved lipid biosynthesis. Importantly, transcripts encoding several key enzymes involved in fatty acid synthesis (FAS) such as ATP citrate lyase (ACLY), fatty acid synthase, and AcCoA carboxylase were markedly upregulated, although not in a Myc-dependent manner. By contrast, transcripts encoding enzymes involved in FAO such as trifunctional protein, carnitine palmitoyltransferase-2 and very long-chain acyl-CoA dehydrogenase were markedly downregulated. Indeed, even transcripts whose encoded enzymes participate in peroxisomal FAO such as the fatty acid transporter ATP-binding cassette-D3, peroxisomal biofunctionalized protein, and acyl-CoA oxidase-1 were downregulated. Functional assays of the FAO pathway were consistent with these findings and showed marked downregulation of FAO activity in both $m y c^{+/+}$and $m y c^{-/-}$tumors (125). Taken together, these studies imply that, unlike the case in fibroblasts, where the loss of Myc leads to a near cessation of both glycolysis and OXPHOS and an upregulation of FAO as an alternate energy source, in HBs, glycolysis and OXPHOS are much less affected and rely less on FAO to supply energy.

\section{METABOLIC LINKS BETWEEN NORMAL AND NEOPLASTIC STATES}

As discussed at length above, proliferating tumor cells require a continual supply of the basic cellular building blocks consisting of amino acids, nucleic acids, and lipids. In this regard, tumor cells are not very different from the progenitor cells that give rise to our various organs during embryogenesis, or the regenerative stem cells now known to reside within many of our adult tissues. Furthermore, differentiated cells may dedifferentiate and then proliferate to repair an injury, followed by re-differentiation. The metabolic similarities between these different types of proliferating cells are striking: all rely heavily upon glucose and glutamine to meet their steep anabolic needs (270-272). Not coincidentally, Myc maintains stem cell pluripotency and self-renewal, perhaps through its effects on driving glucose/glutamine uptake and metabolism (273). On the other end of the spectrum are nonproliferative, differentiated cells that are often metabolically reliant upon FAO. Several fetal tissues that rely upon glucose during growth and development undergo a metabolic switch to FAO after birth. The best-known example of this is the heart (274) and we have made similar observations in human kidney (Goetzman, unpublished data). Senescence is also characterized by a switch to FAO while lipid synthesis is turned off $(275,276)$. With some notable exceptions (i.e., prostate cancer) most cancers are glucose/glutamine dependent and not FAO dependent $(277,278)$.

The glucose/glutamine versus FAO dichotomy is maintained in both normal and neoplastic tissues by a key metabolic phenomenon called the Randle cycle, sometimes simply referred to as the glucose-fatty acid cycle. The Randle cycle refers to the reciprocal nature of mitochondrial rates of pyruvate oxidation and FAO $(279,280)$. The Randle cycle centers on pyruvate dehydrogenase $(\mathrm{PDH})$ and carnitine palmitoyltransferase 1 (CPT1), which are the rate-limiting enzymes of pyruvate oxidation and FAO, respectively. When glucose is abundant and glycolysis is high, pyruvate concentrations rise and inhibit pyruvate dehydrogenase kinase (PDK1), the kinase responsible for phosphorylating and silencing PDH.PDK1 inhibition activates PDH and increases mitochondrial pyruvate oxidation to generate $\mathrm{AcCoA}$ and $\mathrm{NADH}$. Increases in intramitochondrial AcCoA and $\mathrm{NADH}$ have two consequences for FAO. First, the intramitochondrial FAO machinery is directly inhibited by high $\mathrm{NADH} / \mathrm{NAD}^{+}$and $\mathrm{AcCoA} / \mathrm{CoA}$ ratios (281). Second, the entry of pyruvate-derived AcCoA into the TCA cycle produces citrate, which is exported from mitochondria to the cytosol where it is reconverted to AcCoA via the action of ACYL. 
Cytoplasmic AcCoA is then converted to malonyl-CoA by AcCoA carboxylase (ACC). Malonyl-CoA in turn is a potent inhibitor of CPT1. CPT1 is the gatekeeper for FAO via its role in regulating fatty acid transport across the mitochondrial membrane; thus, the result of sustained $\mathrm{PDH}$ flux is the sequestration of fatty acids in the cytosol, away from the degradative FAO machinery. Cytosolic fatty acids are then either converted to triglyceride droplets to fuel the cell should glucose become unavailable, or in the case of proliferating cells, incorporated into phospholipid acyl-chains for synthesizing new membranes. The same malonyl-CoA which silences CPT1 also feeds into the de novo FAS pathway to further support the anabolic needs of the cell (282). Because of this cycle, the rate of $\mathrm{PDH}$ flux has been shown to highly correlate with lipogenesis in many cell types. In the liver, for example, insulin increases PDH activity and lipogenesis from glucose-derived AcCoA, while starvation rapidly inhibits $\mathrm{PDH}$ activity and thus limits glucose-derived lipogenesis (283).

The Randle cycle also works in the opposite direction, i.e., high rates of FAO suppress glucose utilization. In the same way that glucose-derived AcCoA and NADH inhibits the FAO machinery, FAO-derived AcCoA and NADH potently inhibit PDH via activation of PDK1. There is also some evidence that fatty acid-derived citrate exported to the cytosol can suppress glycolysis at the level of phosphofructokinase-1 (284-286). The resulting accumulation of glucose-6-phosphate feeds back to inhibit hexokinase
(HK) and glucose uptake (Figure 5) (286). Overall, the net result of these various points of negative feedback control are a downregulation of glucose utilization by FAO. A key theme of the Randle cycle is that lipogenesis sides with glucose oxidation, and that cells cannot simultaneously conduct FAO and FAS. This is because activation of FAS, by virtue of cytosolic conversion of citrate to AcCoA to malonyl-CoA, would inhibit FAO at the level of CPT1. This maybe the reason why proliferating cells, be they cancerous or not, suppress FAO such that they can drive their absolute requirement for FAS and membrane synthesis. Likewise, it explains how terminally differentiated and senescent cells are able to sustain high rates of FAO for their energetic needs. In short, because of FAO suppression of glucose-derived FAS, it is difficult for cells to proliferate while conducting a high rate of FAO. Exogenous fatty acids can be incorporated into membranes directly, but in FAO-dependent cells the phospholipid synthesis pathways would be in continual competition with mitochondria for incoming exogenous fatty acids.

The Randle cycle and connection between glucose utilization and FAS would suggest that tumors would tend to have low FAO and high FAS. Indeed, this has been observed in many cancers, and inhibition of the FAS pathway has been shown to slow cancer growth in many instances $(287,288)$. In the HB mouse model discussed at length above, FAO was found to be markedly lower than in normal control liver while PDH activity was increased

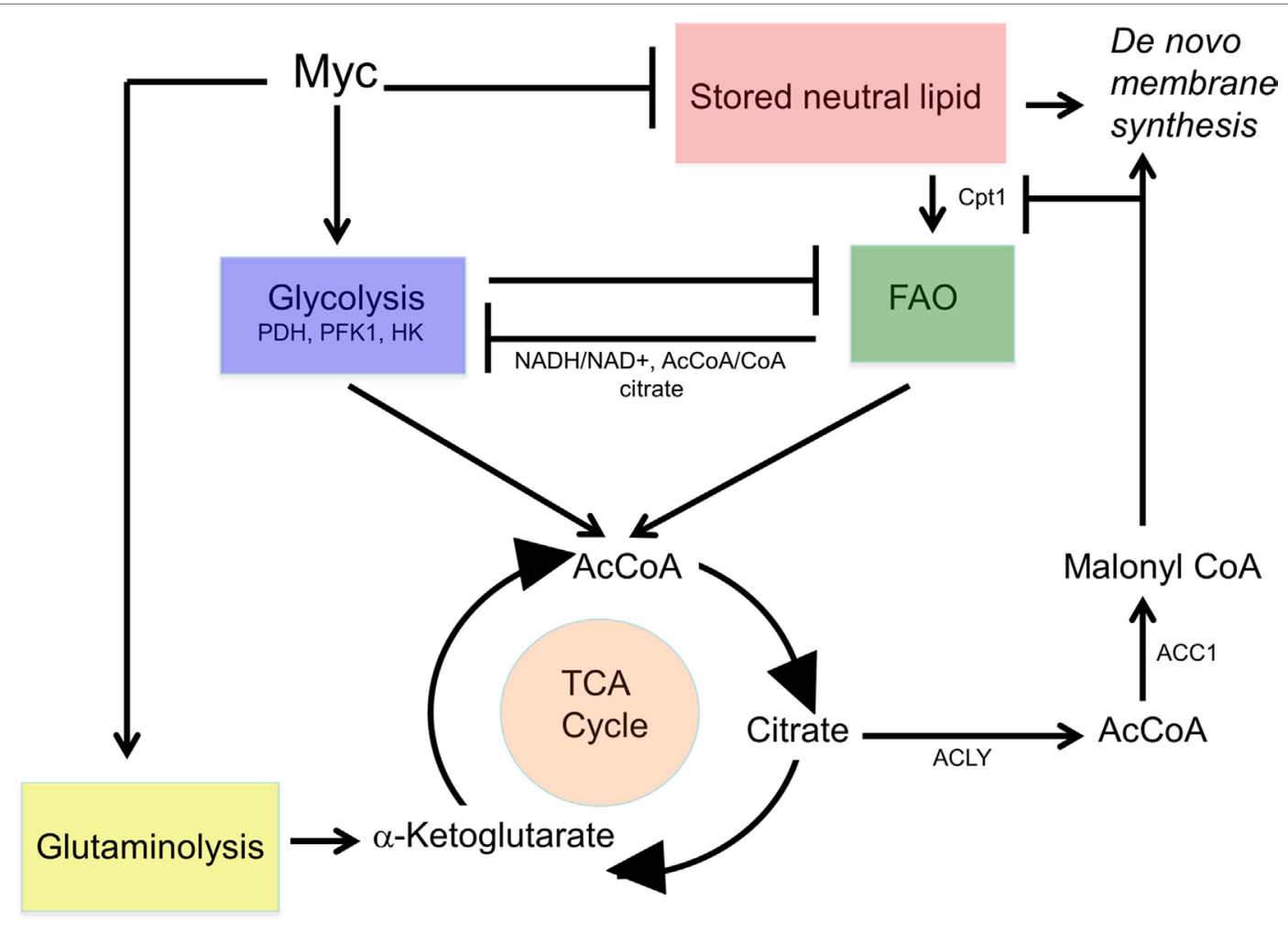

FIGURE 5 | Co-regulation of glycolysis and FAO. Starvation or glucose deprivation mobilizes lipolytic pathways and upregulates FAO to provide an alternate source of acetyl-CoA (AcCoA) and maintain oxidative phosphorylation. More so than glycolysis, FAO increases NADH/NAD+ and AcCoA/coenzyme A ratios as well as cytoplasmic citrate thereby inhibiting pyruvate dehydrogenase (PDH), phosphofructokinase, hexokinase (HK), and glucose uptake (284-286). By contrast, glucose utilization by the TCA cycle tends to produce a greater buildup of citrate-derived, cytoplasmic coenzyme A (CoA) and malonyl-CoA, which exerts potent negative control over Cpt1. 
several-fold (240). This occurred both in the presence and absence of Myc suggesting that there are multiple mechanisms responsible for driving the glucose-fatty acid cycle in tumors. A similar reciprocal relationship between FAO and $\mathrm{PDH}$ activity was also seen in a model of hepatocellular carcinoma induced by the deregulated, doxycycline-regulated induction of Myc (126). Of course, as is true with all aspects of cancer metabolism, there have also been multiple studies demonstrating cancers with the opposite metabolic phenotype, i.e., high FAO and low $\mathrm{PDH}$ activities (289-294). It is interesting to note that prostate cancer, the best-characterized example of a cancer with high FAO, is well known for its typically slow growth rate. Some studies have shown that maximizing pyruvate flux through PDH by inhibiting PDK with dichloroacetate can sensitize cells to other chemotherapies, presumably by promoting mitochondrially driven apoptosis (295). As with many metabolic pathways, too much of any one thing may lead to cell death. In the case of PDH, it has been shown in normal liver that most PDH capacity is not being used, even under fed, insulin-stimulated conditions (283). Only about $10 \%$ of the PDH in fed rodent liver is in the active (unphosphorylated) state; acute insulin exposure doubles this to $20 \%$. Dichloroacetate increased the active state to $100 \%$. Therefore, it remains possible that either supraphysiological activation or inhibition of $\mathrm{PDH}$ may be beneficial in crippling cancer growth, with the usual caveat that it depends upon the cancer being treated.

With regard to liver cancers, the commonality of high $\mathrm{PDH}$ activity in both HBs and HCC $(125,240)$ led to the hypothesis that eliminating PDH may slow tumor growth. First, Jackson et al. examined the consequences of conditional inactivation of the catalytic PDHA1 subunit on normal hepatocyte proliferation in murine liver (240). Using the above-described competitive hepatocyte re-population assay, it was determined that wildtype and PDH knockout hepatocytes contributed equally to the long-term reconstitution of $\mathrm{fah}^{-/-}$recipient livers. Thus, despite the severing of the direct line of communication between glycolysis and the TCA cycle, and between glucose utilization and FAS, proliferation remained unaffected. That PDH is profoundly linked to lipogenesis was demonstrated by the striking loss of lipid stores in PDH KO liver (Figure 6). Based on this observation it is tempting to speculate that $\mathrm{PDH}$ inhibition could represent a novel therapeutic approach for the treatment of NAFLD. What remains to be determined is the magnitude of $\mathrm{PDH}$ suppression needed to achieve this outcome, the length of time PDH suppression must continue, and how rapidly lipid re-accumulates following its reactivation.

Two approaches were next taken to ascertain how inactivation of PDH altered the properties of HBs induced by mutant $\beta$-catenin + YAP $(125,240)$. In the first approach, both the resultant tumors and the adjacent, non-transformed parenchyma were rendered PDH-negative ("pan KO"), whereas in the second, only tumors and not the adjacent non-transformed liver tissue were rendered PDH-negative ("restricted KO"). Survival of the pan KO tumor group did not differ significantly from that of the control group with normal levels of PDH expression in all tissues whereas survival of restricted KO tumor group was significantly prolonged (mean survival $\sim 125$ versus 90 days). Further investigation showed that pan $\mathrm{KO} \mathrm{HBs}$ tended to be smaller than control tumors despite the similar survival of the two groups. By contrast, $\mathrm{HBs}$ from the long-surviving restricted $\mathrm{KO}$ group were about the same size as control tumors. These apparent discrepancies were ultimately resolved by showing that mice in the pan KO group had a severe lactic acidosis at the time of their demise. It was concluded that, in the face of the absence of PDH activity in pan KO hepatocytes, HB-derived lactate could not be metabolized back to pyruvate by the untransformed hepatocytes as it could by the $\mathrm{PDH}$-expressing hepatocytes of restricted $\mathrm{KO}$ mice. The demise of the pan $\mathrm{KO}$ animals was thus due to a combination of tumor burden and lactic acidosis. The normal respiratory compensation that attempts to correct metabolic acidosis was almost certainly compromised in these mice as well due to the restricted diaphragmatic mobility imposed by the tumor burden.

The most notable metabolic defect in PDH KO tumors was a ca. $80 \%$ reduction in total AcCoA levels. Surprisingly, only a slight, statistically non-significant increase in compensatory FAO was observed (240). Importantly, while the Randle cycle shows that driving one pathway will limit the other, these studies suggest that directly limiting one pathway does not necessarily stimulate the other (i.e., eliminating PDH may not necessarily stimulate high FAO). Interestingly and unexpectedly, the PDH KO studies indicated that despite the profound inability to maintain normal levels of AcCoA, KO hepatocytes were able to sustain normal or near-normal rates of growth even following their transformation into highly proliferative tumor cells. It is possible that reductive carboxylation of glutamine, which was not examined, could supply just enough cytosolic AcCoA to drive the fatty acid synthesis needed to supply lipids for new membranes. In this scenario, the minimal induction of compensatory FAO might be explained by glutamine-derived malonyl-CoA, which would limit the capacity for FAO by inhibition of CPT1. In short, this series of studies with PDH KO mice highlight the amazing metabolic plasticity of both normal and neoplastic livers, and stress the difficulty of targeting metabolic pathways to treat cancers.

\section{THERAPEUTIC STRATEGIES AIMED AT TARGETING MYC AND ITS EFFECTORS}

Myc has long been viewed as an exciting but challenging oncologic target $(51,52,296)$. The enthusiasm stems from the fact that Myc is among the most commonly deregulated oncoproteins in all of cancer $(24,51,52,97)$. Even in those neoplasms where Myc deregulation is not immediately appreciable, other oncogenic signaling pathways that are deregulated invariably converge upon Myc which then carries out their transcriptional bidding. In these cases, inhibiting Myc still leads to cell cycle arrest, the collapse of ATP production and apoptosis $(50,191)$. Unfortunately, Myc's lack of enzymatic activity or prominent structural features makes it extremely difficult to target with small molecules (51, 52, 296). The means by which Myc inhibition has been attempted and descriptions of the successes and (mostly) failures along the way have been recently reviewed (297). These attempts included strategies such as altering the structure of Myc DNA-binding sites, inhibiting the structure and/or function of Myc-Max heterodimers, and inhibiting Myc's engagement with and activation 
A

WT

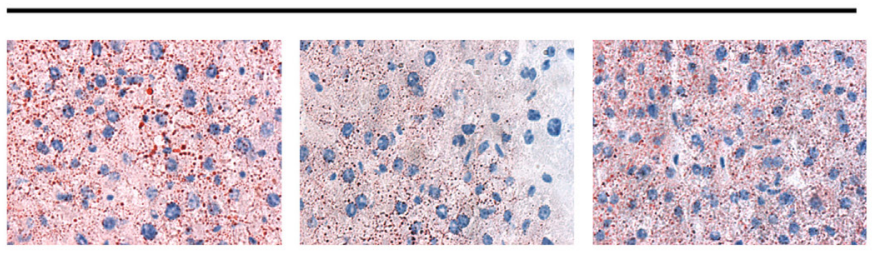

$\mathrm{KO}$

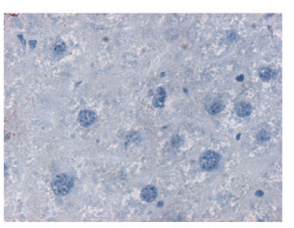

B

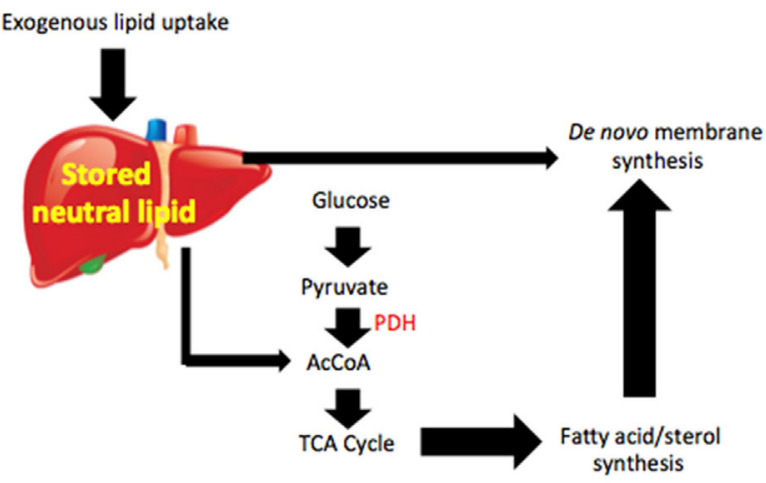

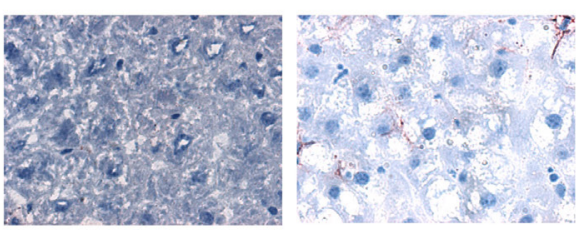

C

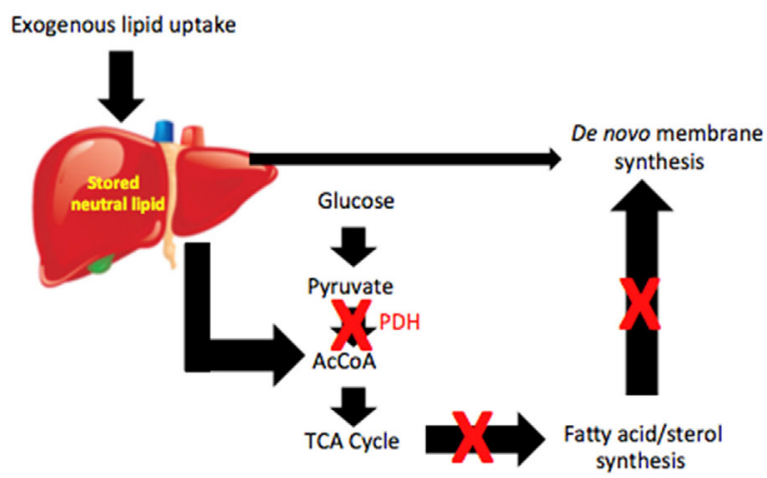

FIGURE 6 | Differential utilization of neutral lipid stores in the absence of pdha1. (A) Oil Red O-stained liver sections from 6- to 8-week-old pdha1 WT and KO mice showing the latter to be nearly devoid of neutral lipid. Each panel is from a different animal. All sections are 40x magnification. (B) Lipid metabolism in the normal [pyruvate dehydrogenase (PDH)-WT] liver where there exists a balance between exogenous lipid uptake, storage, and utilization. The latter consists of direct incorporation of stored lipids into new membranes and FAO. Both of these occur at low levels because they compete with glycolysis to supply acetyl-CoA (AcCoA). The AcCoA derived from glycolysis is used as a substrate for the energy-generating TCA cycle and the energy-depleting synthesis of de novo membrane. (C) Lipid metabolism in PDH KO livers. The activation of FAO provides an alternate source of AcCoA when it cannot otherwise be supplied by glycolysis. Although this route is sufficient to serve as an energy-generating substrate, it is insufficient to allow for de novo fatty acid and sterol synthesis. Thus, stored hepatic lipid is also utilized directly for this purpose. The net result is the depletion of stored neutral lipid reserves.

of the transcriptional activation machinery (297). A second challenge to inhibiting Myc is that the plethora of target genes whose expression is altered, either directly or indirectly, in response to Myc deregulation includes many that are transforming in their own right. Thus, an obvious alternate strategy, such as targeting one of these rather than the intimidating Myc itself, is likely to fail because of their sheer number and oncogenic functional redundancy. A final challenge is that many of the early Myc inhibitors that have been described to date, even those which function well in vitro, have demonstrated disappointing therapeutic efficacy in vivo due to poor tissue penetration, low potency, or rapid metabolism $(51,52,296,297)$.

While these issues are clearly important when considering the targeting of oncogenic pathways, some become less so when contemplating the employment of inhibitors in non-neoplastic settings where Myc is a potential target that may not require systemic inhibition. For example, the intimal hyperplasia that accompanies atherosclerotic stenosis has long been known to be accompanied by and to be dependent upon Myc overexpression $(52,298,299)$. We have proposed that drug-eluting stents, which released Myc inhibitors continuously and over short distances, would provide a means by which high-local compound concentrations could be achieved thus overcoming some of the pharmacologic shortcomings that plague their systemic delivery (52). Myc antisense oligonucleotides have shown efficacy is this regard even though their ability to reduce Myc levels has been somewhat modest $(300,301)$.

Non-neoplastic settings also now permit the consideration of downstream Myc effectors that would not otherwise represent tractable targets due to their neoplastic redundancy as mentioned earlier. An excellent example of this is $\mathrm{PDH}$, which is neither an oncoprotein nor even a direct Myc target although it is dramatically upregulated and activated in response to activation of the Myc pathway (Figure 6) $(125,126,240)$. Inhibiting PDH 
via more traditional approaches than are available for Myc could prove to be of enormous therapeutic benefit for the treatment of NAFLD, a common condition associated with considerable nonneoplastic morbidity and mortality as well being a significant predisposing factor for the development of cancer (257). Time will tell whether the inhibition of Myc and its partners in crime will be of greater therapeutic benefit for cancer, for metabolic disorders, or for those diseases harboring overlapping features of both.

\section{REFERENCES}

1. Deberardinis RJ, Sayed N, Ditsworth D, Thompson CB. Brick by brick: metabolism and tumor cell growth. Curr Opin Genet Dev (2008) 18:54-61. doi:10.1016/j.gde.2008.02.003

2. Vander Heiden MG, Cantley LC, Thompson CB. Understanding the Warburg effect: the metabolic requirements of cell proliferation. Science (2009) 324:1029-33. doi:10.1126/science.1160809

3. Warburg O. On respiratory impairment in cancer cells. Science (1956) 124:269-70.

4. Weinhouse S. The Warburg hypothesis fifty years later. Z Krebsforsch Klin Onkol Cancer Res Clin Oncol (1976) 87:115-26. doi:10.1007/BF00284370

5. Dang CV. Links between metabolism and cancer. Genes Dev (2012) 26:877-90. doi:10.1101/gad.189365.112

6. Hsieh AL, Walton ZE, Altman BJ, Stine ZE, Dang CV. MYC and metabolism on the path to cancer. Semin Cell Dev Biol (2015) 43:11-21. doi:10.1016/j. semcdb.2015.08.003

7. Jin L, Alesi GN, Kang S. Glutaminolysis as a target for cancer therapy. Oncogene (2016) 35:3619-25. doi:10.1038/onc.2015.447

8. Li Z, Zhang H. Reprogramming of glucose, fatty acid and amino acid metabolism for cancer progression. Cell Mol Life Sci (2016) 73:377-92. doi:10.1007/ s00018-015-2070-4

9. Sciacovelli M, Gaude E, Hilvo M, Frezza C. The metabolic alterations of cancer cells. Methods Enzymol (2014) 542:1-23. doi:10.1016/B978-0-12416618-9.00001-7

10. Yang L, Venneti S, Nagrath D. Glutaminolysis: a hallmark of cancer metabolism. Annu Rev Biomed Eng (2017) 19:163-94. doi:10.1146/annurevbioeng-071516-044546

11. Hanahan D, Weinberg RA. Hallmarks of cancer: the next generation. Cell (2011) 144:646-74. doi:10.1016/j.cell.2011.02.013

12. Bardella C, Pollard PJ, Tomlinson I. SDH mutations in cancer. Biochim Biophys Acta (2011) 1807:1432-43. doi:10.1016/j.bbabio.2011.07.003

13. Stein EM. Molecular pathways: IDH2 mutations-co-opting cellular metabolism for malignant transformation. Clin Cancer Res (2016) 22:16-9. doi:10.1158/ 1078-0432.CCR-15-0362

14. Cairns RA, Mak TW. Fire and water: tumor cell adaptation to metabolic conditions. Exp Cell Res (2017) 356:204-8. doi:10.1016/j.yexcr.2017.04.029

15. Kim JY, Lee JY. Targeting tumor adaption to chronic hypoxia: implications for drug resistance, and how it can be overcome. Int J Mol Sci (2017) 18:E1854. doi:10.3390/ijms18091854

16. Nakazawa MS, Keith B, Simon MC. Oxygen availability and metabolic adaptations. Nat Rev Cancer (2016) 16:663-73. doi:10.1038/nrc.2016.84

17. Rosenbloom DIS, Camara PG, Chu T, Rabadan R. Evolutionary scalpels for dissecting tumor ecosystems. Biochim Biophys Acta (2017) 1867:69-83. doi:10.1016/j.bbcan.2016.11.005

18. Boudina S, Abel ED. Mitochondrial uncoupling: a key contributor to reduced cardiac efficiency in diabetes. Physiology (2006) 21:250-8. doi:10.1152/ physiol.00008.2006

19. Kruiswijk F, Labuschagne CF, Vousden KH. p53 in survival, death and metabolic health: a lifeguard with a licence to kill. Nat Rev Mol Cell Biol (2015) 16:393-405. doi:10.1038/nrm4007

20. Tomlinson IP, Novelli MR, Bodmer WF. The mutation rate and cancer. Proc Natl Acad Sci U S A (1996) 93:14800-3. doi:10.1073/pnas.93.25.14800

21. Kato Y, Ozawa S, Miyamoto C, Maehata Y, Suzuki A, Maeda T, et al. Acidic extracellular microenvironment and cancer. Cancer Cell Int (2013) 13:89. doi:10.1186/1475-2867-13-89

\section{AUTHOR CONTRIBUTIONS}

This review manuscript was written and edited by EP and EG. EP designed and prepared the figures.

\section{FUNDING}

This work was supported by NIH grants R01 DK090242 to EG and RO1 CA174713 to EP.

22. Kalkat M, De Melo J, Hickman KA, Lourenco C, Redel C, Resetca D, et al. MYC deregulation in primary human cancers. Genes (Basel) (2017) 8:E151 doi:10.3390/genes8060151

23. Kim JW, Gao P, Liu YC, Semenza GL, Dang CV. Hypoxia-inducible factor 1 and dysregulated c-Myc cooperatively induce vascular endothelial growth factor and metabolic switches hexokinase 2 and pyruvate dehydrogenase kinase 1. Mol Cell Biol (2007) 27:7381-93. doi:10.1128/MCB. 00440-07

24. Nesbit CE, Tersak JM, Prochownik EV. MYC oncogenes and human neoplastic disease. Oncogene (1999) 18:3004-16. doi:10.1038/sj.onc.1202746

25. Walenta S, Mueller-Klieser WF. Lactate: mirror and motor of tumor malignancy. Semin Radiat Oncol (2004) 14:267-74. doi:10.1016/j.semradonc. 2004.04.004

26. Schito L, Semenza GL. Hypoxia-inducible factors: master regulators of cancer progression. Trends Cancer (2016) 2:758-70. doi:10.1016/j.trecan. 2016.10.016

27. Gravina GL, Festuccia C, Popov VM, Di Rocco A, Colapietro A, Sanità P, et al. c-Myc sustains transformed phenotype and promotes radioresistance of embryonal rhabdomyosarcoma cell lines. Radiat Res (2016) 185:411-22. doi:10.1667/RR14237.1

28. Hirschhaeuser F, Sattler UG, Mueller-Klieser W. Lactate: a metabolic key player in cancer. Cancer Res (2011) 71:6921-5. doi:10.1158/0008-5472. CAN-11-1457

29. Mao A, Zhao Q, Zhou X, Sun C, Si J, Zhou R, et al. MicroRNA-449a enhances radiosensitivity by downregulation of c-Myc in prostate cancer cells. Sci Rep (2016) 6:27346. doi:10.1038/srep27346

30. Wang WJ, Wu SP, Liu JB, Shi YS, Huang X, Zhang QB, et al. MYC regulation of $\mathrm{CHK} 1$ and $\mathrm{CHK} 2$ promotes radioresistance in a stem cell-like population of nasopharyngeal carcinoma cells. Cancer Res (2013) 73:1219-31 doi:10.1158/0008-5472.CAN-12-1408

31. Stern R, Shuster S, Neudecker BA, Formby B. Lactate stimulates fibroblast expression of hyaluronan and CD44: the Warburg effect revisited. Exp Cell Res (2002) 276:24-31. doi:10.1006/excr.2002.5508

32. Garrett-Bakelman FE, Melnick AM. Mutant IDH: a targetable driver of leukemic phenotypes linking metabolism, epigenetics and transcriptional regulation. Epigenomics (2016) 8:945-57. doi:10.2217/epi-2016-0008

33. Waitkus MS, Diplas BH, Yan H. Isocitrate dehydrogenase mutations in gliomas. Neuro Oncol (2016) 18:6-26. doi:10.1093/neuonc/nov136

34. Medeiros BC, Fathi AT, DiNardo CD, Pollyea DA, Chan SM, Swords R. Isocitrate dehydrogenase mutations in myeloid malignancies. Leukemia (2017) 31:272-81. doi:10.1038/leu.2016.275

35. Patel KP, Ravandi F, Ma D, Paladugu A, Barkoh BA, Medeiros LJ, et al. Acute myeloid leukemia with IDH1 or IDH2 mutation: frequency and clinicopathologic features. Am J Clin Pathol (2011) 135:35-45. doi:10.1309/ AJCPD7NR2RMNQDVF

36. Dang L, Su SM. Isocitrate dehydrogenase mutation and (R)-2hydroxyglutarate: frombasic discovery to therapeutics development.AnnuRev Biochem (2017) 86:305-31. doi:10.1146/annurev-biochem-061516-044732

37. Kroeze LI, van der Reijden BA, Jansen JH. 5-Hydroxymethylcytosine: an epigenetic mark frequently deregulated in cancer. Biochim Biophys Acta (2015) 1855:144-54. doi:10.1016/j.bbcan.2015.01.001

38. Intlekofer AM, Dematteo RG, Venneti S, Finley LW, Lu C, Judkins AR, et al. Hypoxia induces production of L-2-hydroxyglutarate. Cell Metab (2015) 22:304-11. doi:10.1016/j.cmet.2015.06.023

39. Intlekofer AM, Wang B, Liu H, Shah H, Carmona-Fontaine C, Rustenburg AS, et al. L-2-hydroxyglutarate production arises from noncanonical enzyme 
function at acidic pH. Nat Chem Biol (2017) 13:494-500. doi:10.1038/ nchembio. 2307

40. Nadtochiy SM, Schafer X, Fu D, Nehrke K, Munger J, Brookes PS. Acidic pH is a metabolic switch for 2-hydroxyglutarate generation and signaling. J Biol Chem (2016) 291:20188-97. doi:10.1074/jbc.M116.738799

41. Lussey-Lepoutre C, Buffet A, Gimenez-Roqueplo AP, Favier J. Mitochondrial deficiencies in the predisposition to paraganglioma. Metabolites (2017) 7:E17. doi:10.3390/metabo7020017

42. Settas N, Faucz FR, Stratakis CA. Succinate dehydrogenase (SDH) deficiency, Carney triad and the epigenome. Mol Cell Endocrinol (2017). doi:10.1016/j. mce.2017.07.018

43. Zhao T, Mu X, You Q. Succinate: an initiator in tumorigenesis and progression. Oncotarget (2017) 8:53819-28. doi:10.18632/oncotarget.17734

44. Meyer N, Penn LZ. Reflecting on 25 years with MYC. Nat Rev Cancer (2008) 8:976-90. doi:10.1038/nrc2231

45. Sabnis HS, Somasagara RR, Bunting KD. Targeting MYC dependence by metabolic inhibitors in cancer. Genes (Basel) (2017) 8:E114. doi:10.3390/ genes 8040114

46. Zaytseva O, Quinn LM. Controlling the master: chromatin dynamics at the MYC promoter integrate developmental signaling. Genes (Basel) (2017) 8:E118. doi:10.3390/genes8040118

47. Conacci-Sorrell M, McFerrin L, Eisenman RN. An overview of MYC and its interactome. Cold Spring Harb Perspect Med (2014) 4:a014357. doi:10.1101/ cshperspect.a014357

48. Mannava S, Grachtchouk V, Wheeler LJ, Im M, Zhuang D, Slavina EG, et al. Direct role of nucleotide metabolism in C-MYC-dependent proliferation of melanoma cells. Cell Cycle (2008) 7:2392-400. doi:10.4161/ cc. 6390

49. Soucek L, Whitfield J, Martins CP, Finch AJ, Murphy DJ, Sodir NM, et al. Modelling Myc inhibition as a cancer therapy. Nature (2008) 455:679-83. doi: $10.1038 /$ nature 07260

50. Wang H, Mannava S, Grachtchouk V, Zhuang D, Soengas MS, Gudkov AV, et al. c-Myc depletion inhibits proliferation of human tumor cells at various stages of the cell cycle. Oncogene (2008) 27:1905-15. doi:10.1038/sj. onc. 1210823

51. Fletcher S, Prochownik EV. Small-molecule inhibitors of the Myc oncoprotein. Biochim Biophys Acta (2015) 1849:525-43. doi:10.1016/j.bbagrm. 2014.03.005

52. Prochownik EV, Vogt PK. Therapeutic targeting of Myc. Genes Cancer (2010) 1:650-9. doi:10.1177/1947601910377494

53. Vennstrom B, Sheiness D, Zabielski J, Bishop JM. Isolation and characterization of c-Myc, a cellular homolog of the oncogene (v-Myc) of avian myelocytomatosis virus strain 29. J Virol (1982) 42:773-9.

54. Adams JM, Gerondakis S, Webb E, Corcoran LM, Cory S. Cellular Myc oncogene is altered by chromosome translocation to an immunoglobulin locus in murine plasmacytomas and is rearranged similarly in human Burkitt lymphomas. Proc Natl Acad Sci U S A (1983) 80:1982-6. doi:10.1073/ pnas.80.7.1982

55. Alitalo K, Schwab M, Lin CC, Varmus HE, Bishop JM. Homogeneously staining chromosomal regions contain amplified copies of an abundantly expressed cellular oncogene (c-Myc) in malignant neuroendocrine cells from a human coloncarcinoma. Proc Natl Acad Sci U S A (1983) 80:1707-11. doi:10.1073/pnas.80.6.1707

56. Battey J, Moulding C, Taub R, Murphy W, Stewart T, Potter H, et al. The human c-Myc oncogene: structural consequences of translocation into the IgH locus in Burkitt lymphoma. Cell (1983) 34:779-87. doi:10.1016/0092-8674(83)90534-2

57. Collins S, Groudine M. Amplification of endogenous Myc-related DNA sequences in a human myeloid leukaemia cell line. Nature (1982) 298:679-81. doi:10.1038/298679a0

58. Dalla-Favera R, Bregni M, Erikson J, Patterson D, Gallo RC, Croce CM. Human c-Myc onc gene is located on the region of chromosome 8 that is translocated in Burkitt lymphoma cells. Proc Natl Acad Sci U S A (1982) 79:7824-7. doi:10.1073/pnas.79.24.7824

59. Little CD, Nau MM, Carney DN, Gazdar AF, Minna JD. Amplification and expression of the c-Myc oncogene in human lung cancer cell lines. Nature (1983) 306:194-6. doi:10.1038/306194a0

60. Nishikura K, Ar-Rushdi A, Erikson J, Watt R, Rovera G, Croce CM. Differential expression of the normal and of the translocated human c-Myc oncogenes in B cells. Proc Natl Acad Sci U S A (1983) 80:4822-6. doi:10.1073/ pnas.80.15.4822

61. Rosson D, Tereba A. Transcription of hematopoietic-associated oncogenes in childhood leukemia. Cancer Res (1983) 43:3912-8.

62. Taub R, Kirsch I, Morton C, Lenoir G, Swan D, Tronick S, et al. Translocation of the c-Myc gene into the immunoglobulin heavy chain locus in human Burkitt lymphoma and murine plasmacytoma cells. Proc Natl Acad Sci U S A (1982) 79:7837-41. doi:10.1073/pnas.79.24.7837

63. Armelin HA, Armelin MC, Kelly K, Stewart T, Leder P, Cochran BH, et al. Functional role for c-Myc in mitogenic response to platelet-derived growth factor. Nature (1984) 10:655-60. doi:10.1038/310655a0

64. Blackwood EM, Lüscher B, Kretzner L, Eisenman RN. The Myc:Max protein complex and cell growth regulation. Cold Spring Harb Symp Quant Biol (1991) 56:109-17. doi:10.1101/SQB.1991.056.01.015

65. Callahan M, Cochran BH, Stiles CD. The PDGF-inducible 'competence genes': intracellular mediators of the mitogenic response. Ciba Found Symp (1985) 116:87-97.

66. Campisi J, Gray HE, Pardee AB, Dean M, Sonenshein GE. Cell-cycle control of c-Myc but not c-ras expression is lost following chemical transformation. Cell (1984) 36:241-7. doi:10.1016/0092-8674(84)90217-4

67. Connan G, Rassoulzadegan M, Cuzin F. Focus formation in rat fibroblasts exposed to a tumour promoter after transfer of polyoma plt and Myc oncogenes. Nature (1985) 314:277-9. doi:10.1038/314277a0

68. Coppola JA, Cole MD. Constitutive c-Myc oncogene expression blocks mouse erythroleukaemia cell differentiation but not commitment. Nature (1986) 320:760-3. doi:10.1038/320760a0

69. Cote GJ, Lastra BA, Cook JR, Huang DP, Chiu JF. Oncogene expression in rat hepatomas and during hepatocarcinogenesis. Cancer Lett (1985) 26:121-7. doi:10.1016/0304-3835(85)90017-5

70. Curran T, Bravo R, Müller R. Transient induction of c-fos and c-Myc in an immediate consequence of growth factor stimulation. Cancer Surv (1985) 4:655-81.

71. DePinho RA, Schreiber-Agus N, Alt FW. Myc family oncogenes in the development of normal and neoplastic cells. Adv Cancer Res (1991) 57:1-46. doi:10.1016/S0065-230X(08)60994-X

72. Freytag SO. Enforced expression of the c-Myc oncogene inhibits cell differentiation by precluding entry into a distinct predifferentiation state in G0/G1. Mol Cell Biol (1988) 8:1614-24. doi:10.1128/MCB.8.4.1614

73. Gonda TJ, Metcalf D. Expression of myb, Myc and fos proto-oncogenes during the differentiation of a murine myeloid leukaemia. Nature (1984) 310:249-51. doi:10.1038/310249a0

74. Goyette M, Petropoulos CJ, Shank PR, Fausto N. Regulated transcription of c-Ki-ras and c-Myc during compensatory growth of rat liver. Mol Cell Biol (1984) 4:1493-8. doi:10.1128/MCB.4.8.1493

75. Grosso LE, Pitot HC. Transcriptional regulation of c-Myc during chemically induced differentiation of HL-60 cultures. Cancer Res (1985) 45:847-50.

76. Heldin CH, Betsholtz C, Johnsson A, Nistér M, Ek B, Rönnstrand L, et al. Platelet-derived growth factor: mechanism of action and relation to oncogenes. J Cell Sci Suppl (1985) 3:65-76. doi:10.1242/jcs.1985.Supplement_3.7

77. Holt JT, Redner RL, Nienhuis AW. An oligomer complementary to c-Myc mRNA inhibits proliferation of HL-60 promyelocytic cells and induces differentiation. Mol Cell Biol (1988) 8:963-73. doi:10.1128/MCB.8.2.963

78. Huang JS, Huang SS. Role of growth factors in oncogenesis: growth factor-proto-oncogene pathways of mitogenesis. Ciba Found Symp (1985) 116:46-65.

79. Keath EJ, Caimi PG, Cole MD. Fibroblast lines expressing activated c-Myc oncogenes are tumorigenic in nude mice and syngeneic animals. Cell (1984) 39(2 Pt 1):339-48. doi:10.1016/0092-8674(84)90012-6

80. Kelly K, Cochran BH, Stiles CD, Leder P. Cell-specific regulation of the c-Myc gene by lymphocyte mitogens and platelet-derived growth factor. Cell (1983) 35(3 Pt 2):603-10. doi:10.1016/0092-8674(83)90092-2

81. Kelly K, Cochran B, Stiles C, Leder P. The regulation of c-Myc by growth signals. Curr Top Microbiol Immunol (1984) 113:117-26.

82. Lachman HM, Skoultchi AI. Expression of c-Myc changes during differentiation of mouse erythroleukaemia cells. Nature (1984) 310:592-4. doi:10.1038/310592a0

83. Land H, Parada LF, Weinberg RA. Tumorigenic conversion of primary embryo fibroblasts requires at least two cooperating oncogenes. Nature (1983) 304:596-602. doi:10.1038/304596a0 
84. Makino R, Hayashi K, Sugimura T. C-Myc transcript is induced in rat liver at a very early stage of regeneration or by cycloheximide treatment. Nature (1984) 310:697-8. doi:10.1038/310697a0

85. Müller R, Bravo R, Burckhardt J, Curran T. Induction of c-fos gene and protein by growth factors precedes activation of c-Myc. Nature (1984) 312:716-20. doi:10.1038/312716a0

86. Pfeifer-Ohlsson S, Goustin AS, Rydnert J, Wahlström T, Bjersing L, Stehelin D, et al. Spatial and temporal pattern of cellular Myc oncogene expression in developing human placenta: implications for embryonic cell proliferation. Cell (1984) 38:585-96. doi:10.1016/0092-8674(84)90513-0

87. Prochownik EV, Kukowska J. Deregulated expression of c-Myc by murine erythroleukaemia cells prevents differentiation. Nature (1986) 322:848-50. doi: $10.1038 / 322848 \mathrm{a} 0$

88. Prochownik EV, Kukowska J, Rodgers C. c-Myc antisense transcripts accelerate differentiation and inhibit G1 progression in murine erythroleukemia cells. Mol Cell Biol (1988) 8:3683-95. doi:10.1128/MCB.8.9.3683

89. Macara IG. Oncogenes, ions, and phospholipids. Am J Physiol (1985) 248:C3-11. doi:10.1152/ajpcell.1985.248.1.C3

90. Metcalfe JC, Hesketh TR, Smith GA, Morris JD, Corps AN, Moore JP. Early response pattern analysis of the mitogenic pathway in lymphocytes and fibroblasts. J Cell Sci Suppl (1985) 3:199-228. doi:10.1242/jcs.1985. Supplement_3.19

91. Racker E, Resnick RJ, Feldman R. Glycolysis and methylaminoisobutyrate uptake in rat-1 cells transfected with ras or Myc oncogenes. Proc Natl Acad Sci U S A (1985) 82:3535-8. doi:10.1073/pnas.82.11.3535

92. Nikaido T, Bradley DW, Pardee AB. Molecular cloning of transcripts that accumulate during the late G1 phase in cultured mouse cells. Exp Cell Res (1991) 192:102-9. doi:10.1016/0014-4827(91)90163-O

93. Amati B, Dalton S, Brooks MW, Littlewood TD, Evan GI, Land H. Transcriptional activation by the human c-Myc oncoprotein in yeast requires interaction with Max. Nature (1992) 359:423-6. doi:10.1038/ $359423 \mathrm{a} 0$

94. Amati B, Land H. Myc-Max-Mad: a transcription factor network controlling cell cycle progression, differentiation and death. Curr Opin Genet Dev (1994) 4:102-8. doi:10.1016/0959-437X(94)90098-1

95. Blackwell TK, Kretzner L, Blackwood EM, Eisenman RN, Weintraub H. Sequence-specific DNA binding by the c-Myc protein. Science (1990) 250:1149-51. doi:10.1126/science. 2251503

96. Littlewood TD, Amati B, Land H, Evan GI. Max and c-Myc/Max DNAbinding activities in cell extracts. Oncogene (1992) 7:1783-92.

97. Dang CV, O’Donnell KA, Zeller KI, Nguyen T, Osthus RC, Li F. The c-Myc target gene network. Semin Cancer Biol (2006) 16:253-64. doi:10.1016/j. semcancer.2006.07.014

98. Guo QM, Malek RL, Kim S, Chiao C, He M, Ruffy M, et al. Identification of c-Myc responsive genes using rat cDNA microarray. Cancer Res (2000) 60:5922-8.

99. Kim JW, Dang CV. Cancer's molecular sweet tooth and the Warburg effect. Cancer Res (2006) 66:8927-30. doi:10.1158/0008-5472.CAN-06-1501

100. Campbell KJ, White RJ. MYC regulation of cell growth through control of transcription by RNA polymerases I and III. Cold Spring Harb Perspect Med (2014) 4(5):a018408. doi:10.1101/cshperspect.a018408

101. Dai MS, Lu H. Crosstalk between c-Myc and ribosome in ribosomal biogenesis and cancer. J Cell Biochem (2008) 105:670-7. doi:10.1002/jcb.21895

102. Elend M, Eilers M. Cell growth: downstream of Myc - to grow or to cycle? Curr Biol (1999) 9:R936-8. doi:10.1016/S0960-9822(00)80109-8

103. Gomez-Roman N, Felton-Edkins ZA, Kenneth NS, Goodfellow SJ, Athineos D, Zhang J, et al. Activation by c-Myc of transcription by RNA polymerases I, II and III. Biochem Soc Symp (2006) 73:141-54. doi:10.1042/bss0730141

104. Iritani BM, Eisenman RN. c-Myc enhances protein synthesis and cell size during B lymphocyte development. Proc Natl Acad Sci U S A (1999) 96:13180-5. doi:10.1073/pnas.96.23.13180

105. Johnston LA, Prober DA, Edgar BA, Eisenman RN, Gallant P. Drosophila Myc regulates cellular growth during development. Cell (1999) 98:779-90. doi:10.1016/S0092-8674(00)81512-3

106. Kim S, Li Q, Dang CV, Lee LA. Induction of ribosomal genes and hepatocyte hypertrophy by adenovirus-mediated expression of c-Myc in vivo. Proc Natl Acad Sci U S A (2000) 97:11198-202. doi:10.1073/pnas.200372597

107. Liao DJ, Dickson RB. c-Myc in breast cancer. Endocr Relat Cancer (2000) 7:143-64. doi:10.1677/erc.0.0070143
108. Schlosser I, Hölzel M, Mürnseer M, Burtscher H, Weidle UH, Eick D. A role for c-Myc in the regulation of ribosomal RNA processing. Nucleic Acids Res (2003) 31:6148-56. doi:10.1093/nar/gkg794

109. van Riggelen J, Yetil A, Felsher DW. MYC as a regulator of ribosome biogenesis and protein synthesis. Nat Rev Cancer (2010) 10:301-9. doi:10.1038/ nrc2819

110. Mitchison JM. Growth during the cell cycle. Int Rev Cytol (2003) 226:165-258. doi:10.1016/S0074-7696(03)01004-0

111. Isselbacher KJ. Increased uptake of amino acids and 2-deoxy-D-glucose by virus-transformed cells in culture. Proc Natl Acad Sci U S A (1972) 69:585-9. doi:10.1073/pnas.69.3.585

112. Koppenol WH, Bounds PL, Dang CV. Otto Warburg's contributions to current concepts of cancer metabolism. Nat Rev Cancer (2011) 11:325-37. doi:10.1038/nrc3038

113. Grandori C, Eisenman RN. Myc target genes. Trends Biochem Sci (1997) 22:177-81. doi:10.1016/S0968-0004(97)01025-6

114. Kretzner L, Blackwood EM, Eisenman RN. Transcriptional activities of the Myc and Max proteins in mammalian cells. Curr Top Microbiol Immunol (1992) 182:435-43.

115. Coller HA, Grandori C, Tamayo P, Colbert T, Lander ES, Eisenman RN, et al. Expression analysis with oligonucleotide microarrays reveals that MYC regulates genes involved in growth, cell cycle, signaling, and adhesion. Proc Natl Acad Sci U S A (2000) 97:3260-5. doi:10.1073/pnas.97.7.3260

116. Neiman PE, Ruddell A, Jasoni C, Loring G, Thomas SJ, Brandvold KA, et al. Analysis of gene expression during Myc oncogene-induced lymphomagenesis in the bursa of Fabricius. Proc Natl Acad Sci U S A (2001) 98:6378-83. doi:10.1073/pnas.111144898

117. Nesbit CE, Tersak JM, Grove LE, Drzal A, Choi H, Prochownik EV. Genetic dissection of c-Myc apoptotic pathways. Oncogene (2000) 19:3200-12. doi:10.1038/sj.onc.1203636

118. Schuldiner O, Benvenisty N. DNA microarray screen for genes involved in c-MYC and N-MYC oncogenesis in human tumors. Oncogene (2001) 20:4984-94. doi:10.1038/sj.onc.1204459

119. Yu Q, He M, Lee NH, Liu ET. Identification of Myc-mediated death response pathways by microarray analysis. J Biol Chem (2002) 277:13059-66. doi:10.1074/jbc.M111403200

120. Shim H, Dolde C, Lewis BC, Wu CS, Dang G, Jungmann RA, et al. c-Myc transactivation of LDH-A: implications for tumor metabolism and growth. Proc Natl Acad Sci U S A (1997) 94:6658-63. doi:10.1073/pnas.94. 13.6658

121. Lewis BC, Prescott JE, Campbell SE, Shim H, Orlowski RZ, Dang CV. Tumor induction by the c-Myc target genes $\mathrm{rcl}$ and lactate dehydrogenase $\mathrm{A}$. Cancer Res (2000) 60:6178-83.

122. Shim H, Chun YS, Lewis BC, Dang CV. A unique glucose-dependent apoptotic pathway induced by c-Myc. Proc Natl Acad Sci U S A (1998) 95:1511-6. doi:10.1073/pnas.95.4.1511

123. Dang CV, Le A, Gao P. Myc-induced cancer cell energy metabolism and therapeutic opportunities. Clin Cancer Res (2009) 15:6479-83. doi:10.1158/10780432.CCR-09-0889

124. Soga T. Cancer metabolism: key players in metabolic reprogramming. Cancer Sci (2013) 104:275-81. doi:10.1111/cas.12085

125. Wang H, Lu J, Edmunds LR, Kulkarni S, Dolezal J, Tao J, et al. Coordinated activities of multiple Myc-dependent and Myc-independent biosynthetic pathways in hepatoblastoma. J Biol Chem (2016) 291:26241-51. doi:10.1074/ jbc.M116.754218

126. Dolezal JM, Wang H, Kulkarni S, Jackson L, Lu J, Ranganathan S, et al. Sequential adaptive changes in a c-Myc-driven model of hepatocellular carcinoma. J Biol Chem (2017) 292:10068-86. doi:10.1074/jbc.M117.782052

127. Osthus RC, Shim H, Kim S, Li Q, Reddy R, Mukherjee M, et al. Deregulation of glucose transporter 1 and glycolytic gene expression by c-Myc. J Biol Chem (2000) 275:21797-800. doi:10.1074/jbc.C000023200

128. Bakker BM, Overkamp KM, van Maris AJ, Kötter P, Luttik MA, van Dijken JP, et al. Stoichiometry and compartmentation of NADH metabolism in Saccharomyces cerevisiae. FEMS Microbiol Rev (2001) 25:15-37. doi:10.1111/ j.1574-6976.2001.tb00570.x

129. Grivell AR, Korpelainen EI, Williams CJ, Berry MN. Substrate-dependent utilization of the glycerol 3-phosphate or malate/aspartate redox shuttles by Ehrlich ascites cells. Biochem J (1995) 310(Pt 2):665-71. doi:10.1042/ bj3100665 
130. Boyle RG, Travers S. Hypoxia: targeting the tumour. Anticancer Agents Med Chem (2006) 6:281-6. doi:10.2174/187152006777698169

131. Gilkes DM, Semenza GL, Wirtz D. Hypoxia and the extracellular matrix: drivers of tumour metastasis. Nat Rev Cancer (2014) 14:430-9. doi:10.1038/ nrc3726

132. Vander Heiden MG, Lunt SY, Dayton TL, Fiske BP, Israelsen WJ, Mattaini KR, et al. Metabolic pathway alterations that support cell proliferation. Cold Spring Harb Symp Quant Biol (2011) 76:325-34. doi:10.1101/sqb.2012.76. 010900

133. Mráček T, Drahota Z, Houštěk J. The function and the role of the mitochondrial glycerol-3-phosphate dehydrogenase in mammalian tissues. Biochim Biophys Acta (2013) 1827:401-10. doi:10.1016/j.bbabio.2012.11.014

134. Cinti DL, Cook L, Nagi MN, Suneja SK. The fatty acid chain elongation system of mammalian endoplasmic reticulum. Prog Lipid Res (1992) 31:1-51. doi:10.1016/0163-7827(92)90014-A

135. Porter TD. Electron transfer pathways in cholesterol synthesis. Lipids (2015) 50:927-36. doi:10.1007/s11745-015-4065-1

136. Dayton TL, Jacks T, Vander Heiden MG. PKM2, cancer metabolism, and the road ahead. EMBO Rep (2016) 17:1721-30. doi:10.15252/embr.201643300

137. Hitosugi T, Kang S, Vander Heiden MG, Chung TW, Elf S, Lythgoe K, et al. Tyrosine phosphorylation inhibits PKM2 to promote the Warburg effect and tumor growth. Sci Signal (2009) 2:ra73. doi:10.1126/scisignal.2000431

138. Israelsen WJ, Vander Heiden MG. Pyruvate kinase: function, regulation and role in cancer. Semin Cell Dev Biol (2015) 43:43-51. doi:10.1016/j. semcdb.2015.08.004

139. Tamada M, Suematsu M, Saya H. Pyruvate kinase M2: multiple faces for conferring benefits on cancer cells. Clin Cancer Res (2012) 18:5554-61. doi:10.1158/1078-0432.CCR-12-0859

140. Vander Heiden MG, Locasale JW, Swanson KD, Sharfi H, Heffron GJ, Amador-Noguez D, et al. Evidence for an alternative glycolytic pathway in rapidly proliferating cells. Science (2010) 329:1492-9. doi:10.1126/ science. 1188015

141. Chen M, Zhang J, Manley JL. Turning on a fuel switch of cancer: hnRNP proteins regulate alternative splicing of pyruvate kinase mRNA. Cancer Res (2010) 70:8977-80. doi:10.1158/0008-5472.CAN-10-2513

142. David CJ, Chen M, Assanah M, Canoll P, Manley JL. HnRNP proteins controlled by c-Myc deregulate pyruvate kinase mRNA splicing in cancer. Nature (2010) 463:364-8. doi:10.1038/nature08697

143. Agnihotri S, Zadeh G. Metabolic reprogramming in glioblastoma: the influence of cancer metabolism on epigenetics and unanswered questions. Neuro Oncol (2016) 18:160-72. doi:10.1093/neuonc/nov125

144. Kim KH, Rodriguez AM, Carrico PM, Melendez JA. Potential mechanisms for the inhibition of tumor cell growth by manganese superoxide dismutase. Antioxid Redox Signal (2001) 3:361-73. doi:10.1089/15230860152409013

145. Stefano GB, Kream RM. Cancer: mitochondrial origins. Med Sci Monit (2015) 21:3736-9. doi:10.12659/MSM.895990

146. Monti S, Savage KJ, Kutok JL, Feuerhake F, Kurtin P, Mihm M, et al. Molecular profiling of diffuse large B-cell lymphoma identifies robust subtypes including one characterized by host inflammatory response. Blood (2005) 105:1851-61. doi:10.1182/blood-2004-07-2947

147. Li F, Wang Y, Zeller KI, Potter JJ, Wonsey DR, O’Donnell KA, et al. Myc stimulates nuclearly encoded mitochondrial genes and mitochondrial biogenesis. Mol Cell Biol (2005) 25:6225-34. doi:10.1128/MCB.25.14.6225-6234.2005

148. Asin-Cayuela J, Gustafsson CM. Mitochondrial transcription and its regulation in mammalian cells. Trends Biochem Sci (2007) 32:111-7. doi:10.1016/j. tibs.2007.01.003

149. Bestwick ML, Shadel GS. Accessorizing the human mitochondrial transcription machinery. Trends Biochem Sci (2013) 38:283-91. doi:10.1016/j. tibs.2013.03.006

150. Gaspari M, Larsson NG, Gustafsson CM. The transcription machinery in mammalian mitochondria. Biochim Biophys Acta (2004) 1659:148-52. doi:10.1016/j.bbabio.2004.10.003

151. Adhikary S, Eilers M. Transcriptional regulation and transformation by Myc proteins. Nat Rev Mol Cell Biol (2005) 6:635-45. doi:10.1038/nrm1703

152. Zhou ZQ, Hurlin PJ. The interplay between Mad and Myc in proliferation and differentiation. Trends Cell Biol (2001) 11:S10-4. doi:10.1016/ S0962-8924(01)02121-3

153. Davis AC, Wims M, Spotts GD, Hann SR, Bradley A. A null c-Myc mutation causes lethality before 10.5 days of gestation in homozygotes and reduced fertility in heterozygous female mice. Genes Dev (1993) 7:671-82 doi:10.1101/gad.7.4.671

154. Mateyak MK, Obaya AJ, Adachi S, Sedivy JM. Phenotypes of c-Myc-deficient rat fibroblasts isolated by targeted homologous recombination. Cell Growth Differ (1997) 8:1039-48.

155. Mateyak MK, Obaya AJ, Sedivy JM. c-Myc regulates cyclin D-Cdk4 and -Cdk6 activity but affects cell cycle progression at multiple independent points. Mol Cell Biol (1999) 19:4672-83. doi:10.1128/MCB.19.7.4672

156. Nikiforov MA, Chandriani S, O’Connell B, Petrenko O, Kotenko I, Beavis A, et al. A functional screen for Myc-responsive genes reveals serine hydroxymethyltransferase, a major source of the one-carbon unit for cell metabolism. Mol Cell Biol (2002) 22:5793-800. doi:10.1128/ MCB.22.16.5793-5800.2002

157. Rothermund K, Rogulski K, Fernandes E, Whiting A, Sedivy J, Pu L, et al. $\mathrm{C}-\mathrm{Myc}$-independent restoration of multiple phenotypes by two C-Myc target genes with overlapping functions. Cancer Res (2005) 65:2097-107. doi:10.1158/0008-5472.CAN-04-2928

158. Graves JA, Wang Y, Sims-Lucas S, Cherok E, Rothermund K, Branca MF, et al. Mitochondrial structure, function and dynamics are temporally controlled by c-Myc. PLoS One (2012) 7:e37699. doi:10.1371/journal.pone.0037699

159. Morrish F, Isern N, Sadilek M, Jeffrey M, Hockenbery DM. c-Myc activates multiple metabolic networks to generate substrates for cell-cycle entry. Oncogene (2009) 28:2485-91. doi:10.1038/onc.2009.112

160. Edmunds LR, Sharma L, Kang A, Lu J, Vockley J, Basu S, et al. c-Myc programs fatty acid metabolism and dictates acetyl-CoA abundance and fate. J Biol Chem (2014) 289:25382-92. doi:10.1074/jbc.M114.580662

161. Hardie DG, Ross FA, Hawley SA. AMPK: a nutrient and energy sensor that maintains energy homeostasis. Nat Rev Mol Cell Biol (2012) 13:251-62. doi:10.1038/nrm3311

162. Hardie DG. Molecular pathways: is AMPK a friend or a foe in cancer? Clin Cancer Res (2015) 21:3836-40. doi:10.1158/1078-0432.CCR-14-3300

163. Liu L, Ulbrich J, Müller J, Wüstefeld T, Aeberhard L, Kress TR, et al. Deregulated Myc expression induces dependence upon AMPK-related kinase 5. Nature (2012) 483:608-12. doi:10.1038/nature10927

164. Nieminen AI, Eskelinen VM, Haikala HM, Tervonen TA, Yan Y, Partanen JI, et al. Myc-induced AMPK-phospho p53 pathway activates Bak to sensitize mitochondrial apoptosis. Proc Natl Acad Sci U S A (2013) 110:E1839-48. doi:10.1073/pnas.1208530110

165. Landay M, Oster SK, Khosravi F, Grove LE, Yin X, Sedivy J, et al. Promotion of growth and apoptosis in c-Myc nullizygous fibroblasts by other members of the Myc oncoprotein family. Cell Death Differ (2000) 7:697-705. doi:10.1038/ sj.cdd. 4400701

166. Acin-Perez R, Fernandez-Silva P, Peleato ML, Perez-Martos A, Enriquez JA. Respiratory active mitochondrial supercomplexes. Mol Cell (2008) 32:529-39. doi:10.1016/j.molcel.2008.10.021

167. Cogliati S, Enriquez JA, Scorrano L. Mitochondrial cristae: where beauty meets functionality. Trends Biochem Sci (2016) 41:261-73. doi:10.1016/j. tibs.2016.01.001

168. Chaban Y, Boekema EJ, Dudkina NV. Structures of mitochondrial oxidative phosphorylation supercomplexes and mechanisms for their stabilisation. Biochim Biophys Acta (2014) 1837(4):418-26. doi:10.1016/j. bbabio.2013.10.004

169. Vonck J, Schäfer E. Supramolecular organization of protein complexes in the mitochondrial inner membrane. Biochim Biophys Acta (2009) 1793:117-24. doi:10.1016/j.bbamcr.2008.05.019

170. Hahn A, Parey K, Bublitz M, Mills DJ, Zickermann V, Vonck J, et al. Structure of a complete ATP synthase dimer reveals the molecular basis of inner mitochondrial membrane morphology. Mol Cell (2016) 63:445-56. doi:10.1016/j. molcel.2016.05.037

171. Chen H, Detmer SA, Ewald AJ, Griffin EE, Fraser SE, Chan DC. Mitofusins Mfn1 and Mfn2 coordinately regulate mitochondrial fusion and are essential for embryonic development. J Cell Biol (2003) 160:189-200. doi:10.1083/ jcb.200211046

172. Chen H, Chan DC. Mitochondrial dynamics - fusion, fission, movement, and mitophagy - in neurodegenerative diseases. Hum Mol Genet (2009) 18:R169-76. doi:10.1093/hmg/ddp326

173. Koshiba T, Detmer SA, Kaiser JT, Chen H, McCaffery JM, Chan DC. Structural basis of mitochondrial tethering by mitofusin complexes. Science (2004) 305:858-62. doi:10.1126/science.1099793 
174. Yoon Y, Krueger EW, Oswald BJ, McNiven MA. The mitochondrial protein hFis1 regulates mitochondrial fission in mammalian cells through an interaction with the dynamin-like protein DLP1. Mol Cell Biol (2003) 23:5409-20. doi:10.1128/MCB.23.15.5409-5420.2003

175. Zorzano A, Liesa M, Sebastian D, Segales J, Palacin M. Mitochondrial fusion proteins: dual regulators of morphology and metabolism. Semin Cell Dev Biol (2010) 21:566-74. doi:10.1016/j.semcdb.2010.01.002

176. Chan DC. Fusion and fission: interlinked processes critical for mitochondrial health. Annu Rev Genet (2012) 15:265-87. doi:10.1146/annurev-genet110410-132529

177. Heath-Engel HM, Shore CC. Mitochondrial membrane dynamics, cristae remodelling and apoptosis. Biochim Biophys Acta (2006) 1763:549-60. doi:10.1016/j.bbamcr.2006.02.006

178. Estaquier J, Vallette F, Vayssiere JL, Mignotte B. The mitochondrial pathways of apoptosis. Adv Exp Med Biol (2012) 942:157-83. doi:10.1007/978-94007-2869-1_7

179. Karbowski M. Mitochondria on guard: role of mitochondrial fusion and fission in the regulation of apoptosis. Adv Exp Med Biol (2010) 687:131-42. doi:10.1007/978-1-4419-6706-0_8

180. Sarin M, Wang Y, Zhang F, Rothermund K, Zhang Y, Lu J, et al. Alterations in c-Myc phenotypes resulting from dynamin-related protein 1 (Drp1)mediated mitochondrial fission. Cell Death Dis (2013) 4:e670. doi:10.1038/ cddis. 2013.201

181. Kwong JQ, Henning MS, Starkov AA, Manfredi G. The mitochondrial respiratory chain is a modulator of apoptosis. J Cell Biol (2007) 179:1163-77. doi: $10.1083 /$ jcb. 200704059

182. Lemarie A, Grimm S. Mitochondrial respiratory chain complexes: apoptosis sensors mutated in cancer? Oncogene (2011) 30:3985-4003. doi:10.1038/ onc.2011.167

183. Dagher Z, Ruderman N, Tornheim K, Ido Y. The effect of AMP-activated protein kinase and its activator AICAR on the metabolism of human umbilical vein endothelial cells. Biochem Biophys Res Commun (1999) 1265:112-5. doi:10.1006/bbrc. 1999.1635

184. Dirks AJ, Hofer T, Marzetti E, Pahor M, Leeuwenburgh C. Mitochondrial DNA mutations, energy metabolism and apoptosis in aging muscle. Ageing Res Rev (2006) 5:179-95. doi:10.1016/j.arr.2006.03.002

185. Eguchi Y, Srinivasan A, Tomaselli KJ, Shimizu S, Tsujimoto Y. ATP-dependent steps in apoptotic signal transduction. Cancer Res (1999) 59:2174-81.

186. Kilbride SM, Farrelly AM, Bonner C, Ward MW, Nyhan KC, Concannon CG, et al. AMP-activated protein kinase mediates apoptosis in response to bioenergetic stress through activation of the pro-apoptotic Bcl-2 homology domain-3-only protein BMF. J Biol Chem (2010) 285:36199-206. doi:10.1074/ jbc.M110.138107

187. Leist M, Single B, Castoldi AF, Kuhnle S, Nicotera P. Intracellular adenosine triphosphate (ATP) concentration: a switch in the decision between apoptosis and necrosis. J Exp Med (1997) 185:1481-6. doi:10.1084/jem. 185.8.1481

188. Mukherjee P, Mulrooney TJ, Marsh J, Blair D, Chiles TC, Seyfried TN. Differential effects of energy stress on AMPK phosphorylation and apoptosis in experimental brain tumor and normal brain. Mol Cancer (2008) 7:37. doi:10.1186/1476-4598-7-37

189. Wang H, Hammoudeh DI, Follis AV, Reese BE, Lazo JS, Metallo SJ, et al. Improved low molecular weight Myc-Max inhibitors. Mol Cancer Ther (2007) 6:2399-408. doi:10.1158/1535-7163.MCT-07-0005

190. Wang H, Teriete P, Hu A, Raveendra-Panickar D, Pendelton K, Lazo JS, et al. Direct inhibition of c-Myc-Max heterodimers by celastrol and celastrol-inspired triterpenoids. Oncotarget (2015) 6:32380-95. doi:10.18632/ oncotarget.6116

191. Wang H, Sharma L, Lu J, Finch P, Fletcher S, Prochownik EV. Structurally diverse c-Myc inhibitors share a common mechanism of action involving ATP depletion. Oncotarget (2015) 6:15857-70. doi:10.18632/oncotarget.4327

192. Denis N, Blanc S, Leibovitch MP, Nicolaiew N, Dautry F, Raymondjean M, et al. c-Myc oncogene expression inhibits the initiation of myogenic differentiation. Exp Cell Res (1987) 172:212-7. doi:10.1016/0014-4827(87) 90107-8

193. Chakrabarti A, Gupta K, Sharma JP, Yang J, Agarwal A, Glick A, et al. ATP depletion triggers acute myeloid leukemia differentiation through an ATR/ Chk1 protein-dependent and $\mathrm{p} 53$ protein-independent pathway. J Biol Chem (2012) 287:23635-43. doi:10.1074/jbc.M111.312801
194. Obaya AJ, Mateyak MK, Sedivy JM. Mysterious liaisons: the relationship between c-Myc and the cell cycle. Oncogene (1999) 18:2934-41. doi:10.1038/ sj.onc. 1202749

195. Zörnig M, Evan GI. Cell cycle: on target with Myc. Curr Biol (1996) 6:1553-6. doi:10.1016/S0960-9822(02)70769-0

196. Zirath H, Frenzel A, Oliynyk G, Segerstrom L, Westermark UK, Larsson K, et al. Myc inhibition induces metabolic changes leading to accumulation of lipid droplets in tumor cells. Proc Natl Acad Sci U S A (2013) 110:10258-63. doi:10.1073/pnas.1222404110

197. Yin X, Giap C, Lazo JS, Prochownik EV. Low molecular weight inhibitors of Myc-Max interaction and function. Oncogene (2003) 22:6151-9. doi:10.1038/ sj.onc. 1206641

198. Müller I, Larsson K, Frenzel A, Oliynyk G, Zirath H, Prochownik EV, et al. Targeting of the MYCN protein with small molecule c-Myc inhibitors. PLoS One (2014) 9:e97285. doi:10.1371/journal.pone.0097285

199. van Stipdonk MJ, Hardenberg G, Bijker MS, Lemmens EE, Droin NM, Green DR, et al. Dynamic programming of CD8+ T lymphocyte responses. Nat Immunol (2003) 4:361-5. doi:10.1038/ni912

200. Brand K, Williams JF, Weidemann MJ. Glucose and glutamine metabolism in rat thymocytes. Biochem J (1984) 221:471-5. doi:10.1042/bj2210471

201. Carr EL, Kelman A, Wu GS, Gopaul R, Senkevitch E, Aghvanyan A, et al. Glutamine uptake and metabolism are coordinately regulated by ERK/ MAPK during T lymphocyte activation. JImmunol (2010) 185:1037-44. doi:10.4049/jimmunol.0903586

202. Newsholme EA, Crabtree B, Ardawi MS. The role of high rates of glycolysis and glutamine utilization in rapidly dividing cells. Biosci Rep (1985) 5:393-400. doi:10.1007/BF01116556

203. Wang R, Dillon CP, Shi LZ, Milasta S, Carter R, Finkelstein D, et al. The transcription factor Myc controls metabolic reprogramming upon T lymphocyte activation. Immunity (2011) 35:871-82. doi:10.1016/j.immuni.2011. 09.021

204. Eagle $H$. The specific amino acid requirements of a human carcinoma cell (Stain HeLa) in tissue culture. J Exp Med (1955) 102:37-48. doi:10.1084/ jem.102.1.37

205. DeBerardinis RJ, Cheng T. Q's next: the diverse functions of glutamine in metabolism, cell biology and cancer. Oncogene (2010) 29:313-24. doi:10.1038/onc.2009.358

206. Fernandez-de-Cossio-Diaz J, Vazquez A. Limits of aerobic metabolism in cancer cells. Sci Rep (2017) 7:13488. doi:10.1038/s41598-017-14071-y

207. Reznik E, Wang Q, La K, Schultz N, Sander C. Mitochondrial respiratory gene expression is suppressed in many cancers. Elife (2017) 6:e21592. doi:10.7554/eLife.21592

208. Klimberg VS, McClellan JL. Claude H. Organ, Jr. Honorary lectureship. Glutamine, cancer, and its therapy. Am J Surg (1996) 172:418-24. doi:10.1016/ S0002-9610(96)00217-6

209. Souba WW. Glutamine and cancer. Ann Surg (1993) 218:715-28. doi:10.1097/ 00000658-199312000-00004

210. DeBerardinis RJ, Mancuso A, Daikhin E, Nissim I, Yudkoff M, Wehrli S, et al. Beyond aerobic glycolysis: transformed cells can engage in glutamine metabolism that exceeds the requirement for protein and nucleotide synthesis. Proc Natl Acad Sci U S A (2007) 104:19345-50. doi:10.1073/pnas. 0709747104

211. Pérez-Escuredo J, Dadhich RK, Dhup S, Cacace A, Van Hée VF, De Saedeleer CJ, et al. Lactate promotes glutamine uptake and metabolism in oxidative cancer cells. Cell Cycle (2016) 15:72-83. doi:10.1080/15384101.2015. 1120930

212. Aledo JC, Segura JA, Medina MA, Alonso FJ, Núñez de Castro I, Márquez J. Phosphate-activated glutaminase expression during tumor development. FEBS Lett (1994) 341:39-42. doi:10.1016/0014-5793(94)80236-X

213. Fuchs BC, Bode BP. Amino acid transporters ASCT2 and LAT1 in cancer: partners in crime? Semin Cancer Biol (2005) 15:254-66. doi:10.1016/j.semcancer. 2005.04.005

214. McGivan JD, Bungard CI. The transport of glutamine into mammalian cells. Front Biosci (2007) 12:874-82. doi:10.2741/2109

215. Alberghina L, Gaglio D. Redox control of glutamine utilization in cancer. Cell Death Dis (2014) 5:e1561. doi:10.1038/cddis.2014.513

216. Jiang L, Shestov AA, Swain P, Yang C, Parker SJ, Wang QA, et al. Reductive carboxylation supports redox homeostasis during anchorage-independent growth. Nature (2016) 532:255-8. doi:10.1038/nature17393 
217. Yoo H, Antoniewicz MR, Stephanopoulos G, Kelleher JK. Quantifying reductive carboxylation flux of glutamine to lipid in a brown adipocyte cell line. J Biol Chem (2008) 283:20621-7. doi:10.1074/jbc.M706494200

218. Gardner PR, Raineri I, Epstein LB, White CW. Superoxide radical and iron modulate aconitase activity in mammalian cells. J Biol Chem (1995) 270:13399-405. doi:10.1074/jbc.270.22.13399

219. Yuneva M, Zamboni N, Oefner P, Sachidanandam R, Lazebnik Y. Deficiency in glutamine but not glucose induces Myc-dependent apoptosis in human cells. J Cell Biol (2007) 178:93-105. doi:10.1083/jcb.200703099

220. Wise DR, DeBerardinis RJ, Mancuso A, Sayed N, Zhang XY, Pfeiffer HK, et al. Myc regulates a transcriptional program that stimulates mitochondrial glutaminolysis and leads to glutamine addiction. Proc Natl Acad Sci U S A (2008) 105:18782-7. doi:10.1073/pnas.0810199105

221. Gao P, Tchernyshyov I, Chang TC, Lee YS, Kita K, Ochi T, et al. c-Myc suppression of miR-23a/b enhances mitochondrial glutaminase expression and glutamine metabolism. Nature (2009) 458:762-5. doi:10.1038/nature07823

222. Qing G, Li B, Vu A, Skuli N, Walton ZE, Liu X, et al. ATF4 regulates MYCmediated neuroblastoma cell death upon glutamine deprivation. Cancer Cell (2012) 22:631-44. doi:10.1016/j.ccr.2012.09.021

223. Kaelin WG. Proline hydroxylation and gene expression. Annu Rev Biochem (2005) 74:115-28. doi:10.1146/annurev.biochem.74.082803.133142

224. Loboda A, Jozkowicz A, Dulak J. HIF-1 and HIF-2 transcription factors - similar but not identical. Mol Cells (2010) 29:435-42. doi:10.1007/ s10059-010-0067-2

225. Doe MR, Ascano JM, Kaur M, Cole MD. Myc posttranscriptionally induces HIF1 protein and target gene expression in normal and cancer cells. Cancer Res (2012) 72:949-57. doi:10.1158/0008-5472.CAN-11-2371

226. Ward PS, Thompson CB. Metabolic reprogramming: a cancer hallmark even Warburg did not anticipate. Cancer Cell (2012) 21:297-308. doi:10.1016/j. ccr.2012.02.014

227. Piao L, Fang YH, Parikh K, Ryan JJ, Toth PT, Archer SL. Cardiac glutaminolysis: a maladaptive cancer metabolism pathway in the right ventricle in pulmonary hypertension. J Mol Med (Berl) (2013) 91:1185-97. doi:10.1007/ s00109-013-1064-7

228. Edmunds LR, Otero PA, Sharma L, D'Souza S, Dolezal JM, David S, et al. Abnormal lipid processing but normal long-term repopulation potential of Myc-/- hepatocytes. Oncotarget (2016) 7:30379-95. doi:10.18632/ oncotarget.8856

229. Baena E, Gandarillas A, Vallespinós M, Zanet J, Bachs O, Redondo C, et al. c-Myc regulates cell size and ploidy but is not essential for postnatal proliferation in liver. Proc Natl Acad Sci U S A (2005) 102:7286-91. doi:10.1073/ pnas.0409260102

230. Li F, Xiang Y, Potter J, Dinavahi R, Dang CV, Lee LA. Conditional deletion of c-Myc does not impair liver regeneration. Cancer Res (2006) 66:5608-12. doi:10.1158/0008-5472.CAN-05-4242

231. Qu A, Jiang C, Cai Y, Kim JH, Tanaka N, Ward JM, et al. Role of Myc in hepatocellular proliferation and hepatocarcinogenesis. J Hepatol (2014) 60:331-8. doi:10.1016/j.jhep.2013.09.024

232. Sanders JA, Schorl C, Patel A, Sedivy JM, Gruppuso PA. Postnatal liver growth and regeneration are independent of $\mathrm{c}-\mathrm{Myc}$ in a mouse model of conditional hepaticc-Myc deletion. BMCPhysiol (2012) 12:1. doi:10.1186/1472-6793-12-1

233. Michalopoulos GK. Liver regeneration. J Cell Physiol (2007) 213:286-300. doi:10.1002/jcp. 21172

234. Marongiu F, Serra MP, Sini M, Marongiu M, Contini A, Laconi E. Cell turnover in the repopulated rat liver: distinct lineages for hepatocytes and the biliary epithelium. Cell Tissue Res (2014) 356:333-40. doi:10.1007/ s00441-014-1800-5

235. Miyaoka Y, Ebato K, Kato H, Arakawa S, Shimizu S, Miyajima A. Hypertrophy and unconventional cell division of hepatocytes underlie liver regeneration. Curr Biol (2012) 22:1166-75. doi:10.1016/j.cub.2012.05.016

236. Grompe M, Lindstedt S, al-Dhalimy M, Kennaway NG, Papaconstantinou J, Torres-Ramos CA, et al. Pharmacological correction of neonatal lethal hepatic dysfunction in a murine model of hereditary tyrosinaemia type I. Nat Genet (1995) 10:453-60. doi:10.1038/ng0895-453

237. Overturf K, Al-Dhalimy M, Tanguay R, Brantly M, Ou CN, Finegold M, et al. Hepatocytes corrected by gene therapy are selected in vivo in a murine model of hereditary tyrosinaemia type I. Nat Genet (1996) 12:266-73. Erratum in: Nat Genet (1996) 12:458. doi:10.1038/ng0396-266
238. Kvittingen EA. Tyrosinaemia - treatment and outcome. J Inherit Metab Dis (1995) 18:375-9. doi:10.1007/BF00710049

239. Lindstedt S, Holme E, Lock EA, Hjalmarson O, Strandvik B. Treatment of hereditary tyrosinaemia type I by inhibition of 4-hydroxyphenylpyruvate dioxygenase. Lancet (1992) 340:813-7. doi:10.1016/0140-6736(92)92685-9

240. Jackson LE, Kulkarni S, Wang H, Lu J, Dolezal JM, Bharathi SS, et al. Genetic dissociation of glycolysis and the TCA cycle affects neither normal nor neoplastic proliferation. Cancer Res (2017) 77:5795-807. doi:10.1158/0008-5472. CAN-17-1325

241. Micklem HS, Ford CE, Evans EP, Ogden DA, Papworth DS. Competitive in vivo proliferation of foetal and adult haematopoietic cells in lethally irradiated mice. J Cell Physiol (1972) 79:293-8. doi:10.1002/jcp.1040790214

242. Rejzková J. Competitive repopulation of lethally irradiated mice with cells of various genotypes. Folia Biol (Praha) (1969) 15:346-53.

243. Di Giacomo S, Sollazzo M, Paglia S, Grifoni D. MYC, cell competition, and cell death in cancer: the inseparable triad. Genes (Basel) (2017) 8(4):E120. doi:10.3390/genes8040120

244. Grifoni D, Bellosta P. Drosophila Myc: a master regulator of cellular performance. Biochim Biophys Acta (2015) 1849:570-81. doi:10.1016/j.bbagrm. 2014.06.021

245. Patel MS, Shah HS, Shrivastava N. c-Myc-dependent cell competition in human cancer cells. JCell Biochem (2017) 118:1782-91. doi:10.1002/ jcb. 25846

246. Bettess MD, Dubois N, Murphy MJ, Dubey C, Roger C, Robine S, et al. c-Myc is required for the formation of intestinal crypts but dispensable for homeostasis of the adult intestinal epithelium. Mol Cell Biol (2005) 25:7868-78. doi:10.1128/MCB.25.17.7868-7878.2005

247. Laurenti E, Varnum-Finney B, Wilson A, Ferrero I, Blanco-Bose WE, Ehninger A, et al. Hematopoietic stem cell function and survival depend on c-Myc and N-Myc activity. Cell Stem Cell (2008) 3:611-24. doi:10.1016/j. stem.2008.09.005

248. Muncan V, Sansom OJ, Tertoolen L, Phesse TJ, Begthel H, Sancho E, et al. Rapid loss of intestinal crypts upon conditional deletion of the Wnt/Tcf-4 target gene c-Myc. Mol Cell Biol (2006) 26:8418-26. doi:10.1128/MCB.00821-06

249. Trumpp A, Refaeli Y, Oskarsson T, Gasser S, Murphy M, Martin GR, et al. c-Myc regulates mammalian body size by controlling cell number but not cell size. Nature (2001) 414:768-73. doi:10.1038/414768a

250. Hofmann JW, Zhao X, De Cecco M, Peterson AL, Pagliaroli L, Manivannan J, et al. Reduced expression of MYC increases longevity and enhances healthspan. Cell (2015) 160:477-88. doi:10.1016/j.cell.2014.12.016

251. Leevers SJ, McNeill H. Controlling the size of organs and organisms. Curr Opin Cell Biol (2005) 17:604-9. doi:10.1016/j.ceb.2005.09.008

252. Stanger BZ. Organ size determination and the limits of regulation. Cell Cycle (2008) 7:318-24. doi:10.4161/cc.7.3.5348

253. Lehninger AL, Nelson DI, Cox MM. Principles of Biochemistry. 2nd ed. New York: Worth Publishers (1993). 244, 479 p.

254. Day CP, James OF. Hepatic steatosis: innocent bystander or guilty party? Hepatology (1998) 27:1463-6. doi:10.1002/hep.510270601

255. Lazarin Mde O, Ishii-Iwamoto EL, Yamamoto NS, Constantin RP, Garcia RF, da Costa CE, et al. Liver mitochondrial function and redox status in an experimental model of non-alcoholic fatty liver disease induced by monosodium L-glutamate in rats. Exp Mol Pathol (2011) 91:687-94. doi:10.1016/j. yexmp.2011.07.003

256. Ramadori P, Kroy D, Streetz KL. Immunoregulation by lipids during the development of non-alcoholic steatohepatitis. Hepatobiliary Surg Nutr (2015) 4:11-23. doi:10.3978/j.issn.2304-3881.2015.01.02

257. Brunt EM. Pathology of nonalcoholic fatty liver disease. Nat Rev Gastroent Hepatol (2010) 7:195-203. doi:10.1038/nrgastro.2010.21

258. Mashek DG, Khan SA, Sathyanarayan A, Ploeger JM, Franklin MP. Hepatic lipid droplet biology: getting to the root of fatty liver. Hepatology (2015) 62:964-7. doi:10.1002/hep.27839

259. Tariq Z, Green CJ, Hodson L. Are oxidative stress mechanisms the common denominator in the progression from hepatic steatosis towards nonalcoholic steatohepatitis (NASH)? Liver Int (2014) 34:e180-90. doi:10.1111/ liv. 12523

260. Bell D, Ranganathan S, Tao J, Monga SP. Novel advances in understanding of molecular pathogenesis of hepatoblastoma: a Wnt/ $\beta$-catenin perspective. Gene Expr (2017) 17:141-54. doi:10.3727/105221616Х693639 
261. Cairo S, Armengol C, Buendia MA. Activation of Wnt and Myc signaling in hepatoblastoma. Front Biosci (Elite Ed) (2012) 4:480-6. doi:10.2741/e393

262. Aronovich EL, McIvor RS, Hackett PB. The Sleeping Beauty transposon system: a non-viral vector for gene therapy. Hum Mol Genet (2011) 20(R1):R14-20. doi:10.1093/hmg/ddr140

263. Izsvák Z, Ivics $Z$, Plasterk RH. Sleeping Beauty, a wide host-range transposon vector for genetic transformation in vertebrates. J Mol Biol (2000) 302:93-102. doi:10.1006/jmbi.2000.4047

264. Sawyer GJ, Rela M, Davenport M, Whitehorne M, Zhang X, Fabre JW. Hydrodynamic gene delivery to the liver: theoretical and practical issues for clinical application. Curr Gene Ther (2009) 9:128-35. doi:10.2174/ 156652309787909535

265. Tao J, Calvisi DF, Ranganathan S, Cigliano A, Zhou L, Singh S, et al. Activation of $\beta$-catenin and Yap1 in human hepatoblastoma and induction of hepatocarcinogenesis in mice. Gastroenterology (2014) 147:690-701. doi:10.1053/j.gastro.2014.05.004

266. Wolff JA, Budker V. The mechanism of naked DNA uptake and expression. Adv Genet (2005) 54:3-20. doi:10.1016/S0065-2660(05)54001-X

267. He TC, Sparks AB, Rago C, Hermeking H, Zawel L, da Costa LT, et al. Identification of c-MYC as a target of the APC pathway. Science (1998) 281:1509-12. doi:10.1126/science.281.5382.1509

268. Bhat M, Robichaud N, Hulea L, Sonenberg N, Pelletier J, Topisirovic I. Targeting the translation machinery in cancer. Nat Rev Drug Discov (2015) 14:261-78. doi:10.1038/nrd4505

269. Reznik E, Miller ML, Şenbabaoğlu Y, Riaz N, Sarungbam J, Tickoo SK, et al. Mitochondrial DNA copy number variation across human cancers. Elife (2016) 5:e10769. doi:10.7554/eLife.10769

270. Hu C, Fan L, Cen P, Chen E, Jiang Z, Li L. Energy metabolism plays a critical role in stem cell maintenance and differentiation. Int J Mol Sci (2016) 17:253. doi:10.3390/ijms17020253

271. Lan R, Geng H, Singha PK, Saikumar P, Bottinger EP, Weinberg JM, et al. Mitochondrial pathology and glycolytic shift during proximal tubule atrophy after ischemic AKI. J Am Soc Nephrol (2016) 27:3356-67. doi:10.1681/ ASN.2015020177

272. Shyh-Chang N, Daley GQ, Cantley LC. Stem cell metabolism in tissue development and aging. Development (2013) 140:2535-47. doi:10.1242/dev.091777

273. Cliff TS, Wu T, Boward BR, Yin A, Yin H, Glushka JN, et al. MYC controls human pluripotent stem cell fate decisions through regulation of metabolic flux. Cell Stem Cell (2017) 21:502-16.e9. doi:10.1016/j.stem.2017.08.018

274. Breckenridge RA, Piotrowska I, Ng KE, Ragan TJ, West JA, Kotecha S, et al. Hypoxic regulation of handl controls the fetal-neonatal switch in cardiac metabolism. PLoS Biol (2013) 11:e1001666. doi:10.1371/journal. pbio.1001666

275. Quijano C, Cao L, Fergusson MM, Romero H, Liu J, Gutkind S, et al. Oncogene-induced senescence results in marked metabolic and bioenergetic alterations. Cell Cycle (2012) 11:1383-92. doi:10.4161/cc.19800

276. Wiley CD, Campisi J. From ancient pathways to aging cells-connecting metabolism and cellular senescence. Cell Metab (2016) 23:1013-21. doi:10.1016/j.cmet.2016.05.010

277. DeBerardinis RJ, Chandel NS. Fundamentals of cancer metabolism. Sci Adv (2016) 2:e1600200. doi:10.1126/sciadv.1600200

278. Liu Y. Fatty acid oxidation is a dominant bioenergetic pathway in prostate cancer. Prostate Cancer Prostatic Dis (2006) 9:230-4. doi:10.1038/ sj.pcan. 4500879

279. Randle PJ. Regulatory interactions between lipids and carbohydrates: the glucose fatty acid cycle after 35 years. Diabetes Metab Rev (1998) 14:263-83. doi:10.1002/(SICI)1099-0895(199812)14:4<263::AID-DMR233>3.0.CO;2-C

280. Tumova J, Andel M, Trnka J. Excess of free fatty acids as a cause of metabolic dysfunction in skeletal muscle. Physiol Res (2016) 65:193-207.

281. Abdel-aleem S, Nada MA, Sayed-Ahmed M, Hendrickson SC, St Louis J, Walthall HP, et al. Regulation of fatty acid oxidation by acetyl-CoA generated from glucose utilization in isolated myocytes. JMol Cell Cardiol (1996) 28:825-33. doi:10.1006/jmcc.1996.0077

282. McGarry JD, Takabayashi Y, Foster DW. The role of malonyl-CoA in the coordination of fatty acid synthesis and oxidation in isolated rat hepatocytes. J Biol Chem (1978) 253:8294-300.

283. Holness MJ, Sugden MC. Pyruvate dehydrogenase activities and rates of lipogenesis during the fed-to-starved transition in liver and brown adipose tissue of the rat. Biochem J (1990) 268:77-81. doi:10.1042/bj2680077
284. Bowker-Kinley MM, Davis WI, Wu P, Harris RA, Popov KM. Evidence for existence of tissue-specific regulation of the mammalian pyruvate dehydrogenase complex. Biochem J (1998) 329:191-6. doi:10.1042/bj3290191

285. Harris RA, Bowker-Kinley MM, Huang B, Wu P. Regulation of the activity of the pyruvate dehydrogenase complex. Adv Enzyme Regul (2002) 42:249-59. doi:10.1016/S0065-2571(01)00061-9

286. Hue L, Taegtmeyer H. The Randle cycle revisited: a new head for an old hat. Am J Physiol Endocrinol Metab (2009) 297:E578-91. doi:10.1152/ ajpendo.00093.2009

287. Tanaka M, Masaki Y, Tanaka K, Miyazaki M, Kato M, Sugimoto R, et al. Reduction of fatty acid oxidation and responses to hypoxia correlate with the progression of de-differentiation in HCC. Mol Med Rep (2013) 7:365-70. doi:10.3892/mmr.2012.1201

288. Ventura R, Mordec K, Waszczuk J, Wang Z, Lai J, Fridlib M, et al. Inhibition of de novo palmitate synthesis by fatty acid synthase induces apoptosis in tumor cells by remodeling cell membranes, inhibiting signaling pathways, and reprogramming gene expression. EBioMedicine (2015) 2:808-24. doi:10.1016/ j.ebiom.2015.06.020

289. Basak NP, Banerjee S. Mitochondrial dependency in progression of acute myeloid leukemia. Mitochondrion (2015) 21:41-8. doi:10.1016/j.mito.2015. 01.006

290. Camarda R, Williams J, Goga A. In vivo reprogramming of cancer metabolism by MYC. Front Cell Dev Biol (2017) 5:35. doi:10.3389/fcell.2017. 00035

291. Corbet C, Feron O. Emerging roles of lipid metabolism in cancer progression. Curr Opin Clin Nutr Metab Care (2017) 20:254-60. doi:10.1097/ MCO.0000000000000381

292. Monaco ME. Fatty acid metabolism in breast cancer subtypes. Oncotarget (2017) 8:29487-500. doi:10.18632/oncotarget.15494

293. Rozovski U, Hazan-Halevy I, Barzilai M, Keating MJ, Estrov Z. Metabolism pathways in chronic lymphocytic leukemia. Leuk Lymphoma (2016) 57:758-65. doi:10.3109/10428194.2015.1106533

294. Wu X, Daniels G, Lee P, Monaco ME. Lipid metabolism in prostate cancer. Am J Clin Exp Urol (2014) 2:111-20.

295. Kankotia S, Stacpoole PW. Dichloroacetate and cancer: new home for an orphan drug? Biochim Biophys Acta (2014) 1846:617-29. doi:10.1016/j. bbcan.2014.08.005

296. Horiuchi D, Anderton B, Goga A. Taking on challenging targets: making MYC druggable. American Society of Clinical Oncology (ASCO) Educational Book (2014). p. e497-502. doi:10.14694/EdBook_AM.2014.34.e497

297. Whitfield JR, Beaulieu ME, Soucek L. Strategies to inhibit Myc and their clinical applicability. Front Cell Dev Biol (2017) 5:10. doi:10.3389/ fcell.2017.00010

298. de Nigris F, Sica V, Herrmann J, Condorelli G, Chade AR, Tajana G, et al. c-Myc oncoprotein: cell cycle-related events and new therapeutic challenges in cancer and cardiovascular diseases. Cell Cycle (2003) 2(4):325-8. doi:10.4161/cc.2.4.414

299. Badimon L, Badimon JJ, Penny W, Webster MW, Chesebro JH, Fuster V. Endothelium and atherosclerosis. J Hypertens Suppl (1992) 10(2):S43-50.

300. De Feo M, Forte A, Onorati F, Renzulli A, Cipollaro M, Cotrufo M, et al. Rat carotid arteriotomy: c-Myc is involved in negative remodelling and apoptosis. J Cardiovasc Med (Hagerstown) (2006) 7:61-7. doi:10.2459/01. JCM.0000199779.92967.59

301. Forte A, Galderisi U, De Feo M, Gomez MF, Esposito S, Santè P, et al. c-Myc antisense oligonucleotides preserve smooth muscle differentiation and reduce negative remodelling following rat carotid arteriotomy. J Vasc Res (2005) 42:214-25. doi:10.1159/000085379

Conflict of Interest Statement: The authors declare that the research was conducted in the absence of any commercial or financial relationships that could be construed as a potential conflict of interest.

Copyright (c) 2018 Goetzman and Prochownik. This is an open-access article distributed under the terms of the Creative Commons Attribution License (CC BY). The use, distribution or reproduction in other forums is permitted, provided the original author(s) and the copyright owner are credited and that the original publication in this journal is cited, in accordance with accepted academic practice. No use, distribution or reproduction is permitted which does not comply with these terms. 